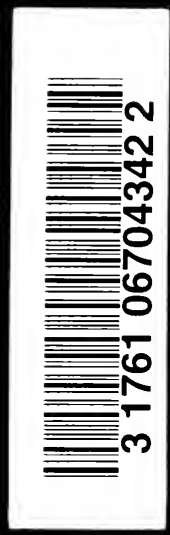




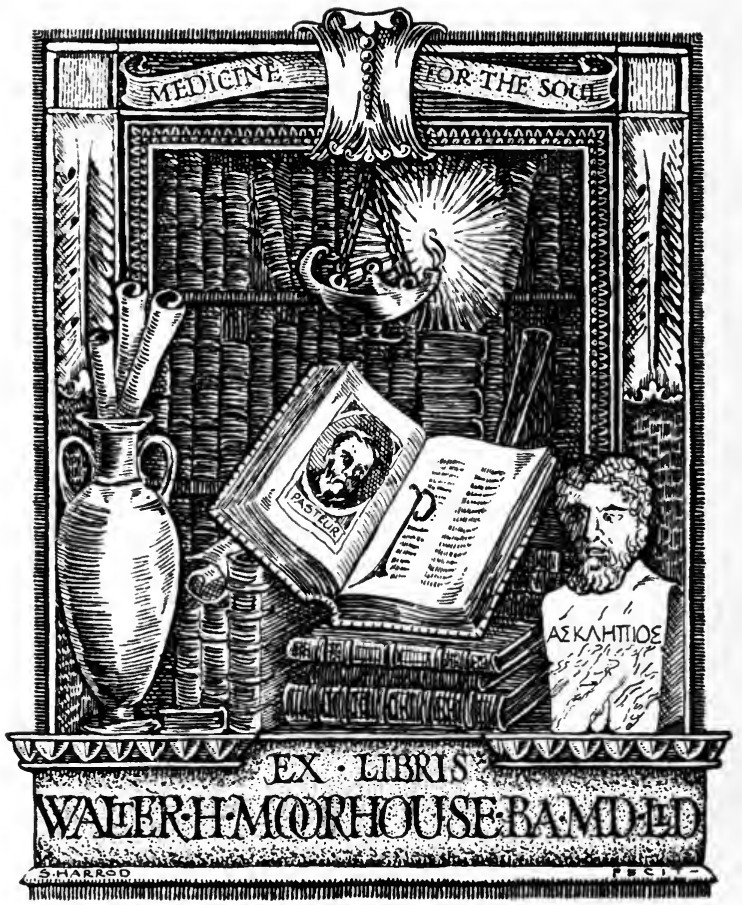



THE PROGNOSIS AND TREATMENT OF DISEASES OF THE HEART 
Digitized by the Internet Archive in 2007 with funding from

Microsoft Corporation 
$M C$ dee 26,13 .

THE

PROGNOSIS AND TREATMENT

OF

\title{
DISEASES OF THE HEART
}

\author{
R. O. MOON \\ M.A., M.D. OxON., F.R.C.P.
}

PHYSICIAN TO THE NATIONAL HOSPITAL FOR DISEASES OF THE HEART

ASSISTANT PHYSICIAN TO THE ROYAL, WATBRLOO HOSPITAL

REISSUE

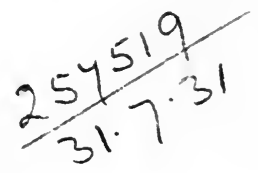

THE MACMILLAN COMPANY OF CANADA, LTD.

TORONTO

19I 3 
First published October 1912. 


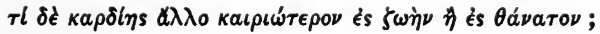

Aretaeus.

Si donc on joignait à la précision moderne quelque chose de la prévoyance antique, c'est-à-dire si on s'accoutumait à combiner, avec le diagnostique particulier du siège ou de l'espèce de la maladie, le diagnostique général auquel Hippocrate donnait le nom de prognose; on utiliserait, au profit de la médecine contemporaine, des idées et des études qui ont beaucoup servi, et qui peuvent servir encore; de telle sorte que je vois, dans l'étude du Pronostic d'Hippocrate, un double avantage: le practicien peut $\mathrm{y}$ apprendre à assurer sa pratique; et le pathologiste, à developper certains côtés de la science qui sont restés dans l'ombre.

LITTRE. 



\section{PREFACE}

In the course of the ages the heart, like other organs of the body, has been viewed in a great variety of ways. In ancient times it seems to have been regarded as a sort of heel of Achilles, in that it was held to be immune to all ordinary diseases. It was not unnatural that the inability to detect cardiac abnormalities should lead to the belief that the heart itself could not become diseased. Even the great discovery of Harvey was not followed by any immediate increase in the knowledge of cardiac pathology. True, indeed, Raymond Vieussens of Montpellier (I64I-I7I6) was able to recognise disease of the heart as the cause of affections termed asthma and hydrothorax, to notice the characteristic pulse of aortic insufficiency and to describe mitral stenosis and the consequent stagnation of the blood in the vessels of the lungs, while Morgagni (I68I-I77I) was able to distinguish between hypertrophy and dilatation of the heart, and to know that disease of the right side of the heart gives rise to stasis in the 
lungs and pulmonary hæmorrhages, yet it was not till the invention of the stethoscope and increased practice of percussion that cardiac diseases began to be seriously studied by clinical physicians. The recognition of murmurs and valvular lesions caused an importance to be attached to them out of all proportion to their intrinsic value; doubtless some observers early in the nineteenth century did direct attention to the importance of the condition of the cardiac muscle, but the differentiation and study of the physics of murmurs proved a more exciting study and perhaps rightly so, since we did not then possess the instrumental means of estimating the strength of the heart's muscle that we had for estimating the significance of murmurs. The study of cardiac arrhythmia, which was begun by Dr. Mackenzie and Professor Wenckebach and carried on most brilliantly by Dr. Lewis and many others, opens up a new field of cardiac research, and it may be that the advent of the string galvanometer will be as fruitful for purposes of prognosis as the stethoscope has been for diagnosis. These possibilities, however, lie in the womb of time, and in the present state of our knowledge it would be unwise to lay too much stress on electrocardiographic curves for purposes of prognosis till more work has been done on the subject. There are fashions in medicine as in everything else, and there is now a tendency to 
attach less importance to cardiac lesions than our immediate predecessors were in the habit of doing, for it has been realised that hearts, though damaged in various ways, are still capable of excellent service, and that cardiac disease is no necessary bar to a good deal of useful activity. Heart disease, though for the laity it may still spell sudden death, for the profession has long ceased of necessity to mean anything of the kind, and while a "weak heart" is still a source of much unnecessary invalidism, this is probably more often due to fussy friends and relations than the outcome of the specific advice given by the medical attendant. In putting together this little book I need hardly say how much I am indebted to the writings of such well known authorities as Professors Osler and Clifford Allbutt and Dr. James Mackenzie in this country, to Babcock in America, to Krehl, Jürgensen and V. Leyden in Germany and particularly to Huchard in France. 



\section{CONTENTS}

CHAP. PAGE

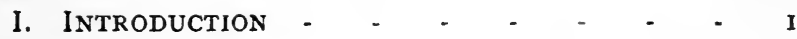

II. AORTIC DISEASE -

III. Mitral and Tricuspid Disease - - $\quad 24$

IV. MYOCARDITIS - - - - - - 46

V. ANgINA Pectoris - $\quad$ - $\quad$ - $\quad$ - $\quad$ - $\quad 68$

VI. Functional AfFections and Heart Strain 78

VII. Paroxysmal Tachycardia aNd STOKESADAMS' DISEASE - $\quad$ - $\quad$ - $\quad$ - $\quad$ - $\quad$ - 87

VIII. PERICARDITIS - $\quad$ - $\quad$ - $\quad$ - $\quad$ - $\quad$ - 97

IX. The Treatment of Special Symptoms - - 104 



\section{CHAPTER I.}

INTRODUCTION.

THE heart, which is the centre of the whole circulatory system, and therefore responsible for the distribution of blood to every part of the body, may have its mechanism interfered with in a great variety of ways; roughly speaking, however, we may say that there are three main directions, in which it can be affected so as to disturb the necessary distribution of the blocd.

(I) The integrity of one or more of the valves may be so impaired, that either the orifice is unduly narrowed, thus impeding the passage of the blood, or the valvular flaps may fail to coapt after the systolic contraction, so that blood regurgitates back through them.

(2) The muscle of the heart may be damaged in different ways, so that its contractility is lessened, and consequently the ventricular stroke is weakened.

(3) Functional perturbations of the heart's activity. 
The first thing to realise about heart disease is that the heart may be damaged either in its valves or its muscle, without giving rise to any symptoms at all. The heart, when examined for insurance or in some routine way, may disclose a valvular murmur, an irregular or intermittent pulse, of which there has been given no subjective evidence. Now assuming this murmur to be due to structural disease, it merely informs us that that particular heart is not so good a mechanism as some other heart which has no valvular lesion or pulse irregularity. Since, ex hypothesi, there are no cardiac symptoms, the case requires no treatment, at the same time it does affect the prognosis, and more especially is it important when the case is one for insurance. Here a number of factors must be considered, such as the cause of the valvular lesion, whether due to rheumatism, chorea or scarlet fever on the one hand, or whether induced by excess of alcohol, lues, overstrain or a part of general arterial degeneration.

Great as has been the increase in our power of diagnosing cardiac lesions during the past century, our skill in prognosis has hardly increased pari passu. Certainly there are now known a large number of facts about the heart, which affect the prognosis, but to foretell with reasonable accuracy the course of a case at an early stage is still largely beyond the power of most of us. Those specially 
skilled in prognosis still have to rely mainly on

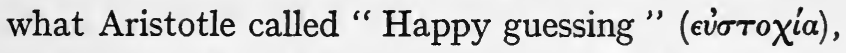
or what we should perhaps term " clinical acumen." Another sphere of life furnishes us with a similar illustration. The immense amount of labour in Europe which has been devoted to the study of history of late years has resulted in a vast increase in the accurately ascertainable facts of history and in the knowledge of certain principles which would seem to regulate the evolution of political systems and of society, yet the statesman must still rely far more on his political instinct than on his detailed knowledge of history. His judgment will always be based on something more than the sum total of the analysed data before him, and this too is true of the physician. Put briefly, the power of foretelling the future, whether in political affairs or in medical prognosis, is still more of an art than a science. One of the classical distinctions between an art and a science is that the latter can be taught, whereas an art cannot. As was said by a brilliant man of letters, "Nothing worth knowing can be taught." Consequently we must recognise that it is hardly possible to formulate anything in the nature of definite rules for the prognosis of heart disease, we can only give such hints and suggestions as it is to be hoped may be useful in cultivating that clinical insight, which is so essential if one is to form a 
correct prognosis in a given case of heart disease. The treatment of heart disease is, as a rule, well understood when we have before us conditions of pronounced cardiac failure, but it is more complex and subtle, when, with the heart apparently compensated, we are confronted with cases of dyspepsia or general weakness, in which it is most difficult to be sure that direct treatment of the heart will be the best line to take. It is an entirely common experience to find two cases with almost identically the same dyspeptic symptoms, yet the one has a pronounced valvular lesion, while the circulatory system of the other is, to all appearance, healthy. Hence, one of the great problems of heart disease is this : are the symptoms we meet with independent of the cardiac lesion, or do they directly follow from it? Clearly this will affect considerably both our prognosis and treatment.

In the matter of prognosis it is easy to attach undue importance to small points; this tendency has been fostered by the apparent increasing complexity of cardiac cases, owing to the added refinements of auscultation and percussion, not to mention new aspects of the shape of the heart revealed to us by Röntgen Rays, new meaning attached to bloodpressure, and increased facilities for measuring it with accuracy. It may be that the electrocardiograph has in store for us a means for giving a precise 
prognosis beyond anything which we can at present contemplate. When, however, actually confronted with a case of heart disease, there would seem to be certain broad lines, upon which we must decide the two important questions: (I) How long is the patient likely to live? (2) How far will he be able to lead an efficient life? Our own impression is that an answer to these questions can be given, which, if reasonable care has been exercised, may generally prove fairly correct, though the increasing knowledge of cardiac phenomena may for a time seem to bewilder rather than to enlighten us.

That heart disease is not necessarily so serious as the laity usually imagine was known to Laennec, who writes, "On réussit à faire vivre pendant de longues années certains malades avec des affections du cœur plus ou moins graves." 


\section{CHAPTER II.}

AORTIC DISEASE.

Aortic stenosis has often been called " the lesion of longevity." Such an expression would hardly have been used, had it been customary in the past to have been more rigid in diagnosis. A systolic murmur heard over the aortic area is no sound evidence of narrowing of that orifice; in later life such murmurs are perhaps the most common of all, but taken alone they do not justify us in diagnosing true (stenosis. Assuming, however, that there is a real narrowing at the aortic valves, as evidenced by a thrill and systolic murmur in the aortic area, together with perhaps some smallness and retardation of the pulse (and an absent or diminished aortic second sound) what is to be our prognosis?

In all cases of aortic disease, the most important point to determine with regard to the prognosis is the cause, i.e. whether the obstruction at the aortic orifice has arisen as a sequel to acute endocarditis, induced it may be by rheumatism, chorea, or scarlet 
fever, or whether it is part of a slow sclerosing degenerative process. The former cases are sometimes conveniently classified as cardiac, the latter as arterial. Now, the arterial form of pure aortic stenosis is much the less common of the two, for the simple reason that the general sclerosing process, which gives rise to the obstruction at the aortic orifice, also renders the aortic valves incompetent. In the cases of this kind which do arise the prognosis is certainly worse than in those of the cardiac form of obstruction, because the lesion is almost necessarily progressive, frequently involving the coronary arteries, and so leading to degeneration of the myocardium with a tendency to attacks of angina.

More common undoubtedly are those cases of aortic stenosis which arise in connection with acute endocarditis, and here the prognosis is distinctly better, as the lesion may well remain stationary for a considerable time, unless another attack of rheumatic fever damages the valves still further. In a young and otherwise healthy individual the left ventricle readily hypertrophies to satisfy the demand caused by the obstruction, and in some degree this hypertrophy advances pari passu with any increase in the obstruction. It can thus be easily understood how cases of this kind may live out the normal span of life, engaging in a fair amount of activity, 
tempered with a reasonable caution: thus a young man E. B., aged r9, came up to my out-patients in I904 on account of shortness of breath during the preceding three months.- He showed well-marked evidence of aortic stenosis, there being a systolic thrill in the aortic area, and also a loud rasping murmur there, audible a few inches from the chest wall, the pulse-rate being 64 and of low tension. $\mathrm{He}$ had had scarlet fever $2 \frac{1}{2}$ years previously, and his cardiac lesion doubtless dated from that time, although he had only had symptoms for three months. He soon improved under treatment, and has twice since then come up to see me at intervals of three years, but each time he has had nothing to complain of ; he is a stove-fitter by trade, but avoids lifting any heavy weights, and he never experiences any shortness of breath, unless he runs. Probably he will be able to live out a full term of life, taking only quite ordinary precautions. It is this lesion which is most often associated with loud rasping murmurs audible at a distance from the chest wall, which, however, in no way affects the prognosis.

In all valvular affections, when the heart is compensated, the practical point to realise is that the subject has little or no capital to draw upon, for the ordinary reserve power of the heart is being continuously expended to maintain the necessary compensation, the heart in fact is living up to its 
income. The early symptoms of a failing compensation, such as praecordial distress and dyspnoea, on exertion must be carefully noted, for when once compensation has failed in a case of aortic stenosis, our power to restore it is less than in the case of other valvular lesions.

Speaking generally, there is no inherent tendency to sudden death in aortic stenosis, as there is in aortic regurgitation, but the left ventricle grows slowly weaker, and so tends to a gradual and not a sudden dilatation. Still, though far from common, sudden death in aortic stenosis does sometimes occur, possibly the obstruction at the aortic orifice prevents the coronary arteries from being properly filled or a high degree of stenosis gives rise to an extreme anaemia of the brain. More often the continued high pressure in the left ventricle affects the mitral valve, which gives way, and we have the signs of mitral regurgitation. For a short time this yielding at the mitral orifice, by acting as a safety valve to the left ventricle, may seem beneficial, but the increased pressure soon makes itself felt in the pulmonary circulation, and all the ill results of backward pressure ensue. Such a condition of things in a case of simple mitral regurgitation may be removed again and again by rest and suitable treatment, but when there is an irremovable obstacle at the aortic orifice, little permanent good can be expected from 
any line of treatment. The serious symptoms, which show themselves as compensation is failing, are always respiratory. The patient has severe attacks of dyspnoea and orthopnoea, a bad cough often develops, and there may be pulmonary hæmorrhage. Jürgensen (quoting Bamberger) mentions that in $I_{5}$ cases of marked aortic stenosis (most of them with some insufficiency) 7 showed either attacks of pulmonary hæmorrhage during life or hæmorrhagic infarcts in the lung at autopsy. ${ }^{\mathbf{1}}$

Aortic stenosis has often been found associated with pulmonary tuberculosis, thus Babcock mentions 7 cases out of 20 of aortic stenosis as being due to this cause, so that aortic stenosis may be said to be favourable to the development of phthisis, perhaps in consequence of the general malnutrition which is induced by obstruction at the aortic orifice; this contingency should therefore be considered in making a prognosis, particularly if there is any family history of tuberculosis.

Aortic Regurgitation.-Here, again, in considering ing the prognosis, a recognition of the cause of the lesion is of primary importance, and, as has been said above in connection with aortic stenosis, it is well to divide the cases into cardiac and arterial, the former carrying with them a more favourable prognosis, because the lesion is apt to remain stationary,

${ }^{1}$ Nothnagel's Encyclopaedia, p. 408. (English Edition.) 
and the main cause for apprehension is chiefly the immediate mechanical result upon the left ventricle, whereas the arterial cases are essentially progressive, being part of a widespread degenerative process, so that one cannot expect compensation to last long.

This lesion is nearly always accompanied with great hypertrophy of the left ventricle, the extent of which may be regarded as some index of the amount of regurgitation, and it is the concomitant cardiac hypertrophy which gives rise to the symptoms of headache, dizziness and disturbance of vision so frequent in aortic cases, while the cerebral anaemia often renders intellectual work difficult, and may give rise to great irritability of temper. The increased volume of blood, which is discharged with increased force at each systole into the aorta and arterial system, produces a continually recurring strain on the arterial walls, thus giving rise to chronic inflammation of their coats, and often to dilatation of the aorta, and it is in these cases specially that pain and symptoms of angina arise. As the left ventricle becomes dilated-which is always an unfavourable sign-there will develop a secondary mitral insufficiency, so that the case may present itself clinically for the purpose of treatment as a mitral one; caeteris paribus the greater the dilatation of the left ventricle in aortic regurgitation, the worse is the prognosis. 
In young subjects it is astonishing how effective the compensation may be in those cases which have been caused by acute endocarditis. The patient with a greatly hypertrophied heart, loud murmurs, most obviously pulsating arteries in the neck, and with the general circulation thrown completely out of gear, may still be able to lead a fairly active life, and, in the case of the labouring classes, to do quite hard work far beyond what one would $a$ priori have believed to be possible. Still, though compensation may be maintained in spite of hard work for quite a long time, continuance with such work can never be advisable ; there must always be a risk of breakdown when the heart is living fully up to its income, so to speak, and then to restore the equilibrium is a difficult task, and usually the compensation is obtained at a lower level of cardiac efficiency. However satisfactorily the heart may be working, we must never forget the risks to which it is exposed from intercurrent diseases such as rheumatism, influenza and pneumonia. There is always, too, the risk of cerebral embolism, and pulmonary apoplexy may occur, though this is much less common than in mitral cases. Sudden death from syncope or inhibition may befall young patients who are apparently doing satisfactorily ; this, however, is more rare than is generally believed. As showing the power of the heart in an aortic case, 
which has resulted from endocarditis, the following is a striking example: (I) " $\mathrm{H}$. C., aged 34 , had rheumatic fever when he was Io years old. At the age of 22 he was refused admission to the Post Office on account of his heart, but he had had no cardiac symptoms till he was attacked by pneumonia in Jan., I905, since which time he had been greatly troubled with palpitation, thumping of the heart and dyspnoea on slight exertion. The pneumonia had evidently put a severe strain upon the heart and brought about rupture of compensation. When I first saw him (in I905) he had the well-marked signs and symptoms of aortic disease and the pulse was intermittent, altogether I was inclined to give a bad prognosis : however, treatment in the hospital for a couple of months improved him very much. Four years later I heard from his doctor that he had come through another attack of pneumonia satisfactorily; when one remembers the great strain which pneumonia puts upon the heart I think to have passed through two attacks of pneumonia in 4 years with a most pronounced aortic lesion is a great success. It should be added, however, that he was a man of healthy and temperate habits, always a matter of great importance in heart disease. (2) At the present time (IgI2) I have under my care at the hospital a woman aged 44 who is suffering from aortic regurgitation due to 
rheumatism. She has had five attacks of rheumatic fever, the first at the age of I4 and the second at the age of 20 , when the heart was affected. She came before me six years ago for palpitation of the heart and breathlessness when she had already suffered from the lesion for I8 years. She is a dressmaker and only quite occasionally has to stop away from work; at the time of writing (24 years after the onset of the disease) her general condition is certainly better than when I first saw her 6 years ago. Doubtless the prognosis of aortic disease, as of other cardiac lesions, is better in the case of women than in the case of men. Von Leyden speaks of cases of aortic regurgitation lasting from $I_{5-20}$ years, and he knew a man who for 15 years had had no trouble from this lesion. ${ }^{1}$

In the arterial cases we are confronted with the fact that the disease is almost necessarily progressive, though with judicious treatment the condition may remain stationary for a time it can never really improve, owing to the changes which take place in the coronary arteries. It is these changes in the coronary arteries which give rise to the most serious symptoms connected with aortic disease, namely angina pectoris, which is serious not only on account of the intense pain and alarming condition of the patient, but because it indicates that there ${ }^{1}$ Deutsch. Med. Woch. 1889, p. 285. 
is probably considerable degeneration of the cardiac muscle and the consequent likelihood of sudden death. In those arterial forms of aortic disease which own lues as a cause, and these since the advent of the Wassermann method of diagnosis seem to be increasingly numerous, one should be specially careful in giving a prognosis; though the symptoms in these cases can be more readily alleviated by iodide of potassium than in other forms of the disease, there seems to be a greater liability to sudden death, probably due to the fact that the myocardium no less than the aorta has been damaged by the luetic poison.

As to the physical signs in connection with the prognosis, it may be said generally that the more collapsing the pulse, the greater will be the regurgitation, but it must be remembered that the collapsing pulse is more noticeable in the aortic disease of young subjects, due to rheumatism, which otherwise carry with them a more favourable prognosis than the arterial cases with the less collapsing pulse. Changes in the character of the murmurs are generally not of much importance; alterations in the cardiac dulness are more valuable, an increase in the transverse area of dulness being usually a bad sign, whereas the increase vertically may be a good one.

An intermittent pulse has a more important significance in an aortic case than it has in mitral 
disease; yet too much weight should not be attached to this sign as indicating a bad prognosis. I. have had under observation for some six years a middle-aged man with well-marked aortic disease and a decidedly irregular pulse, yet he has been free from cardiac symptoms all that time. Broadbent used to lay stress on the condition of the second sound in the aortic area and over the carotids, and no doubt when this is entirely obliterated by the diastolic murmur, it does indicate that the amount of regurgitation is considerable. Professor Clifford Allbutt also draws attention to the serious significance of muscular effort, no longer raising the blood-pressure but reducing it. But the actual power of the heart to meet its daily work cannot be estimated by any small and meticulous points. More importance should be attached to heredity and the general family history, also to the temperament of the individual, as some temperaments by their equability act as an important reinforcement to treatment.

Treatment.-So long as compensation is maintained, there is certainly no need for any active treatment to be undertaken, but clearly a heart with some narrowing of the aortic orifice or incompetence of the aortic valves is in a more precarious state than one which is not so affected, consequently, though the patient may not require treatment, $h$ 
does require care. Thus when the aortic disease has been due to acute endocarditis, the important thing is to guard against any fresh attack of rheumatism, or even of influenza, which may cause further damage to the valves. In young subjects who have passed the age of puberty some latitude may be allowed as regards games. Of course, anything in the nature of long distance running, swimming or football (except as a behind), or any games involving competition must be ruled out of court, but with reasonable care tennis, fives, cricket and bicycling might be permitted. Much, of course, must depend on how far the patient can be trusted to desist from the exercise when he finds himself becoming more breathless than usual, or suffers from palpitation, or has a sense of exhaustion. As regards manual labour, it is surprising how much can be accomplished with comparative impunity in the case of young men, and perhaps for a few years it may not do them any particular harm, but, having once engaged in manual labour, it becomes increasingly difficult after a time to change to a more sedentary employment now that labour tends to become so highly specialised. Consequently, no young man with aortic disease should be allowed to embark on work which involves any serious amount of manual labour. When the aortic lesion appears in later life as part of a general arterial degeneration, 
then the most important question during the period of compensation is one of diet and exercise together with the avoidance of such things as make for arterio-sclerosis. Excess either in food or drink is bad for everybody, but especially for those in whom the aortic valves are not sound. With regard to exercise, no arbitrary rule can be laid down, each patient must find out his own limitations for himself, but in any case he should be careful about walking uphill, or against a wind, or making any sudden movements.

In all treatment of heart disease, one must naturally guard against a rash and careless mode of life, which may day by day render the lesion worse ; on the other hand, it is equally important to avoid making the patient into an invalid. It is the business of the physician so to order the life of his patient that he may be able to make the best of himself. Handicapped as he is by the cardiac lesion, he may yet, if wisely guided, lead a much more satisfactory life than one who is possessed of a better physical equipment. In a certain sense, all of us are handicapped in one direction or another; the mere fact of having to eat, drink, and sleep inhibit activities which might be possible to more ethereally constituted creatures, and the cardiac lesion may be regarded as simply one further addition to these handicapping circumstances. Everyone 
has limitations, and one of the arts of life consists in discovering them; everyone who wishes to accomplish anything must set bounds to his activities, so as to obtain the necessary concentration of purpose ("Der etwas grosses will muss sich zusammenraffen "). A friend of the writer, who had been paraplegic for 25 years, once told him that one of the advantages of being paralysed was that it enabled a man to know his limitations, so that less time is wasted in the pursuit of activities, for which one is really unfitted, and that if we could only diagnose our own mental and moral paralysis, our life would be much more effectively employed. Few things will exercise the tact of the physician more than the question of a man's occupation. Should he give it up altogether, and with it perhaps the main interest of his life? As a rule, in the case of a labouring man, unless he has reached the position of a foreman or some such post, in which the actual manual work is but slight, he will be wise if he gives it up altogether. Because a man becomes incapacitated for his particular work, it is not necessary that he should do no work: perhaps, as society becomes better organised, it may be possible to adjust employments better, and a man with a weakened heart may find it easier to get a job suited to his impaired physique, and we shall not see strong and powerfully built men toiling at 
sedentary pursuits, while those of a more delicate fibre are engaged in manual labour. If the interests only of the individual were considered, a compensated cardiac lesion should not be a disqualification for the Civil Service. In the higher walks of life, politics, business, journalism and the professions, more will depend upon temperament than upon calling. One man, from a natural imperturbability or from an acquired philosophic calm, which comes from viewing all mundane things in their true proportion, may continue to bear with impunity the weight of an empire, while another may find too much for him the daily petty annoyances of some small and obscure business. One lady as head of a college might be able to continue her work there with satisfaction to herself and everyone else, while another may fret her spirit to decay by constant frictions with a kitchenmaid. In the case of both sexes much depends upon the kind of carapace with which most sensible people provide themselves as a protection against the minor ills of life. The physician should not view the problem in too mechanical a way; it is not merely a question of the number of hours of work which have to be considered, but it is the amount of emotional or, if we may so express it, the psychic wear and tear which is of importance.

When compensation has actually broken down, 
and there are symptoms of dyspnoea on exertion, giddiness and palpitation, then it will be reasonable to adopt a more definite line of treatment.

r. Rest.-Nothing at the first indication of breaking compensation is more valuable than knocking off work at once and actually resting in bed; in the case of aortic disease at this stage, a week or so in bed and for some time longer complete freedom from work, will generally be effective in restoring the heart to its previous condition of compensation.

2. Diet is, of course, a matter of the first importance, particularly in the arterial cases of aortic disease, but it is hard to lay down precise rules; each case must be judged on its merits. We are naturally anxious to avoid increasing the arterial resistance, and therefore we diminish very largely nitrogenous foods, but when thrown upon a diet consisting mainly of carbohydrates, to which the patient has perhaps been unaccustomed in the past, he often readily develops dyspepsia and flatulence together with all the evils for the heart which may flow from them, though, doubtless, speaking generally, dyspeptic symptoms are not so common in aortic as in mitral disease.

Restriction of fluid should always be insisted on, as we do not want to increase the output of the left ventricle ; in particular, if a heavy meal is eaten, no fluid should be taken with it. The meals should 
be small and light, and approximately equal in amount, instead of having one heavy meal and two quite small ones.

3. Drugs.-In the case of aortic disease, one cannot hope to give the same assistance to the heart by means of medicine as is possible in the case of the mitral lesion; our efforts must be rather indirect or simply confined to the relief of symptoms (of which more will be said later on). In the arterio-sclerotic cases there is no doubt that benefit is derived from a prolonged course of iodides, quite apart from any question of lues. Some help may be obtained from strychnine and arsenic, specially the latter in moderate doses. Broadbent used to speak highly of phosphorus, and I have certainly found it useful in many cases. It frequently happens in aortic disease that the mitral valve gives way, and then we have all the results of backward pressure-dropsy, enlarged liver, and oedema of the lungs; here digitalis may be employed as effectively as in mitral disease, for the case has, ex hypothesi, become primarily mitral, but when these symptoms have disappeared, it is best to discontinue the digitalis, for by slowing the heart and increasing peripheral resistance it augments the reflux of blood without any corresponding advantage. In cases of aortic stenosis, when the compensation has broken down, if we find increased cardiac action with a 
quick low tension pulse indicating that the systole of the ventricle does not afford sufficient time for the ventricle to discharge its contents adequately through the narrowed orifice, then small doses of digitalis, e.g. $\mathrm{m} \mathrm{v}-\mathrm{x}$ of the tincture, perhaps combined with iron, will be found very useful. Although the prolongation of the diastole produced by digitalis is per se undesirable in aortic regurgitation, at the same time, if we have reason to believe that the cardiac muscle is fairly sound, moderate doses of digitalis by causing the systolic contractions to be more sustained will counterbalance this disadvantage. Of course, we shall never see the same striking results with digitalis in aortic disease as we do in mitral cases ; its administration should always be somewhat exceptional in aortic cases. When digitalis is given in the cases of arteriosclerotic origin, it is well to combine it with some vaso-dilator, and in such cases it is important to keep a careful watch upon the pulse. 


\section{CHAPTER III.}

MITRAL DISEASE.

Mitral regurgitation.-At the outset we must distinguish between mitral regurgitation due to damaged valves, and that caused by anaemic conditions, which enfeeble the contractile power of the cardiac musculature, thus preventing the auriculoventricular aperture from being sufficiently contracted, so that the valves, though themselves healthy, cannot close the orifice. By mitral regurgitation is meant, of course, a reflux of blood from the left ventricle into the left auricle, and the most definite evidence of this is to be found in a systolic murmur at the apex, heard with or replacing the first sound, and conducted externally to the left axilla and to the back near the angle of the scapula. This sign may be regarded as practically pathognomonic of the fact that there is a reflux of blood from the left ventricle to the left auricle, though, taken by itself, it gives no absolute indication as to whether the regurgitation is due to organic disease 
of the valves or to weakness of the cardiac muscle. In the case of children, it should be noted that there may be a doubt sometimes of diagnosing even regurgitation from such a systolic murmur, for this sign may be caused by a roughening of (or fibrinous exudation on) the pericardium in the neighbourhood of the apex.

That form of mitral regurgitation which is often called functional is due, as we have described, to weakness of the cardiac musculature and may, doubtless, be abolished by the improved nutrition of the muscle, yet persistent anaemia is capable of producing a fatty condition of the cardiac muscle which it may not be possible to remedy.

Prognosis.-It has long been recognised that uncomplicated cases of mitral regurgitation due to endocarditis, which has been caused by rheumatic fever, chorea, or scarlet fever, afford the most hopeful outlook of all the valvular lesions, and particularly so when scarlet fever is the cause of the endocarditis, as there is so little likelihood of its occurring a second time. When confronted by cases of this kind, in which the heart is well compensated, and there are consequently no cardiac symptoms, the prognosis may be most favourable. The way in which such cases are rejected for insurance, or for the public services, gives an entirely false conception of their intrinsic severity; for these cases may continue on 
to an advanced age and with really very little illhealth, provided a moderate amount of care is taken. The main danger lies in the liability to further attacks of rheumatism, any one of which may damage the already existing cardiac lesion, and the whole aspect of the case may be thus entirely changed. Then, too, it is not always possible to be certain at a single interview that the lesion due to endocarditis may not be progressive, so that the patient, without undertaking any extra exertion, or doing anything imprudent, may gradually develop serious symptoms. It would seem that the same remarks should hold good of chorea, yet I have noticed in several instances that mitral regurgitation due to chorea, when fully established, is more intractable to treatment than when it is due to rheumatic fever; though there is no difference in the physical signs, it may be that there is in some cases a greater tendency for the myocardium to be affected. On the other hand, there are undoubtedly many instances in which the signs of mitral regurgitation following chorea eventually disappear, that is, the valvular lesion does not become fully established. In fact, the late Sir Andrew Clarke stated that he had never found mitral regurgitation due to chorea persisting after ro years. Speaking generally, young children under ro years of age readily succumb to this heart lesion, whereas in 
older children and young people the prognosis is often most favourable.

Insurance companies naturally attach very great importance to the condition of the heart. No one, of course, could pass a heart as sound with mitral regurgitant murmurs due to rheumatism, and yet what amount of practical importance should be attached to it in estimating the expectation of life ? In a case of this kind it is wise to lay great stress upon the hereditary history. Assuming the proposer comes of a long-lived stock without any strong rheumatic history, and in other respects appears healthy, there is little reason why the fact of having mitral regurgitation should prevent him from living out the full span of life. All that the lesion implies is that he has a smaller amount of cardiac reserve to draw upon, and the mere fact of knowing this, if explained to him in a sensible manner, will be sufficient to deter him from putting any excessive strain upon his heart. The main danger to which he is exposed would be the chance of having another attack of rheumatism, which might cause further damage to the heart. It should, however, be remembered that the likelihood of rheumatism inflicting further injury on the heart diminishes with advancing years.

As contrasted with aortic disease, the striking thing to realise is that mitral regurgitation is so 
much more amenable to treatment. Serious as a rupture of compensation in all cardiac cases must necessarily be, it is perhaps less serious in mitral regurgitation than in the case of any other valvular lesion. Again and again the heart may temporarily break down with dropsy and all the signs of backward pressure, and again and again by judicious treatment the patient may be restored to his former condition of health; it is this power of recovery under treatment which gives to mitral regurgitation when of endocarditic origin its favourable prognosis.

As in the case of the aortic valves, so also the mitral valves, though less frequently, may be affected by arterio-sclerosis-the "insuffisance mitral-artérielle". of Huchard-which is usually caused by gout, lead poisoning, or dietetic excesses, and is often associated with renal disease. In these cases the murmur is apt to be rough and sawlike, and is conducted less to the axilla and back. Here, as in all cases of arterio-sclerosis, dyspnoea is a prominent symptom, and the prognosis is far less favourable than in the endocarditic forms of valvular lesion, owing to the progressive tendency of the sclerotic change and the age of the patient, which renders it likely that the myocardium will no longer remain healthy. These are the cases in which the prognosis is so much affected by the condition of arterial tension, for everything depends upon the 
amount of resistance in the peripheral systemic circulation; it is therefore to the lessening of this peripheral resistance that treatment has to be mainly directed rather than to stimulating the cardiac muscle. If, with a given degree of mitral incompetence, there is undue arterial tension, the force of the regurgitant stream will be great, there will be considerable backward pressure in the left auricle, and pulmonary circulation and the demand made upon the right ventricle will be severe, all which circumstances very readily give rise to structural changes. Still, with reasonable care as regards diet and the avoidance of mental and physical stress and strain as far as possible, even cases of mitral regurgitation, due to arterio-sclerosis, may be able to lead a satisfactory life for some years. The first signs of dilatation as evidenced by increase in the transverse diameter of the cardiac dulness, and the situation of the apex beat below and external to the nipple line, naturally influence the prognosis unfavourably. These cases have generally a tendency to catarrh of the bronchi, which is a serious sign, and becomes of greater gravity the more the finer bronchi are involved. When the lesion is connected with renal sclerosis, a cantering sound at the apex, implying as it does excessive tension in the left ventricle, is nearly always of evil omen. Death may occasionally come rapidly from 
pneumonia or from cardiac thrombosis or embolism of the large vessels, but sudden death is rare, except in those cases connected with arterio-sclerosis, in which the myocardium is so often extensively involved.

Treatment.-In the cases arising from acute endocarditis rest is of primary importance, which may mean a couple of months in the recumbent position, and certainly six months before the ordinary avocations are resumed; similarly when regurgitation through the mitral valve arises from dilatation caused by some acute febrile disease a period of absolute rest is most necessary. In the case of young children from 5 to $I_{4}$ this insistence upon rest is very important; after that age compensation usually establishes itself more readily, and the ultimate prognosis is better. But, of course, the existence of valvular disease in a child increases the danger from the acute diseases to which childhood is specially liable, namely, scarlet fever, diphtheria, pertussis and pneumonia. In quite early childhood the muscular walls of the heart are less resistant, so that rapid dilatation occurs more readily than in adult life; children too are more liable to intercurrent attacks of rheumatism, which may damage the heart still further. In childhood a generally poor nutrition and unhygienic surroundings have a particularly bad effect upon the heart, which at 
that time has to provide for the growth as well as for the ordinary wear and tear of the body. Consequently, in the case of young subjects plenty of fresh air, good food, and hygienic surroundings are of the first importance. Special care should be taken to guard against a fresh attack of rheumatism ; the child should wear woollen clothing next to its skin, and not go out too readily in cold damp weather. Where it is possible to choose a climate one should select a dry and moderately bracing place, with plenty of sunshine, and a house on gravel soil with a southerly aspect.

Meals should be small, and in particular all excess of starchy foods and sweets must be avoided, which so readily give rise to flatulence and acidity; there is no objection to nitrogenous food being taken by children in ordinary quantities. Exercise in moderation is undoubtedly good for children, when their valvular lesion is well compensated. All competitive games should be ruled out, but there is no reason why bicycling, if the patient will walk up the hills, riding, rowing, skating, and also cricket should not be permitted in moderation. Even in cases of wellcompensated heart lesions it is well for a child to lie down for half an hour every day; of course, when shortness of breath, palpitation of the heart, or pulmonary congestion indicate failing compensation, then rest becomes imperative; it need not perhaps 
be absolute, but it will certainly mean lying down for the larger part of the day. It may then be necessary to employ specific heart tonics, and children take digitalis very well; at the same time, in these early stages of failing compensation, I have generally found that small doses of arsenic and iron are very effective.

Special care must be taken as the time of puberty approaches; in particular, one must be careful to prevent over-pressure at school, and it is advisable that no serious employment should be engaged in till puberty is well passed.

On the other hand, the systolic apex murmur with but little regurgitation, so common after middle age, and associated generally with arteriosclerosis, requires little direct treatment beyond restriction of diet, and exercise so far from being diminished, should be encouraged, and a sedentary, self-indulgent life modified. More of these cases than is generally supposed with the main lesion at the mitral orifice are of luetic origin, and respond well to full doses of iodide of potassium. The more detailed aspects of treatment, however, will be considered when we come to speak of myocarditis; for, from a therapeutic standpoint, there is no difference between a lesion of the cardiac muscle and an uncompensated valve lesion.

Mitral stenosis differs from mitral regurgitation 
in the fact that it is always an organic lesion, and can never be produced by conditions of anaemia and bad nutrition, such as we have seen to be the case in mitral regurgitation. Though, in the main, the aetiology of the two diseases is the same, yet there is this striking fact, that mitral stenosis is less definitely associated with rheumatism than is mitral regurgitation; it is more often found connected with the less pronounced forms of rheumatism. We are all familiar with those cases of mitral stenosis among women, for which no rheumatic history can be found, and when there is a rheumatic antecedent it is so often rheumatism in its less noticeable forms, i.e. vague, indefinite pains in the limbs, stiff neck, etc.; so much is this the case, that it has often seemed not improbable that in the case of children endocarditis may be the only manifestation of rheumatism. Mitral stenosis is not a common lesion in childhood, and in my experience it has been quite unusual to see a child under ro years with clear evidence of this lesion; this may be partly owing to the fact that mitral stenosis, being due to the slow contraction of the fibrous tissue of the valves, takes some time to develop, and also to the fact that the left auricle in young subjects does not contract with sufficient force to give rise to the auriculo-systolic, or what is more commonly called the praesystolic murmur. 
Prognosis.-The lesion of mitral stenosis has been rightly considered to carry with it a more serious prognosis than mitral regurgitation, but it must be remembered that there are many cases of regurgitation, the organic nature of which is not so easy to determine ; consequently some of these functional regurgitations may become included in the lists of organic mitral regurgitations, thus favourably affecting the prognosis, whereas in the case of mitral stenosis, with the possible exception of a Flint's murmur, there is never any doubt as to the structural character of the lesion. An insurance company will seldom accept a case known to suffer from mitral stenosis, and it is certainly a fact that one comparatively seldom meets with this lesion in men or women who are well past middle life, which points to a relatively early death.

That mitral stenosis may exist for some years without any pronounced cardiac symptoms is within the experience of all. How often do we not come across women between the ages of $I 7$ and 30 , complaining perhaps of indigestion, headache, or general malaise, when examination discloses the typical thrill and praesystolic murmur at the apex. The symptoms are readily removed by some very simple treatment, and it may be some years before the patient again appears with signs of a definitely broken compensation. No doubt the greater tran- 
quillity and more sedentary character of the lives of most women enable them to be less affected by the lesion than are men. Once, however, the compensation has broken down, it is not so easily restored as is that of mitral regurgitation, for the narrowing of the mitral orifice causes an imperfect filling of the left ventricle, so that the heart obtains an insufficient supply of blood, and cardiac weakness is thereby promoted. Mitral stenosis when established in late childhood has a more serious prognosis than if it first occurs in adult life, partly owing to the progressive tendency of the constriction of the orifice, which is more marked in early life, and partly owing to the fact that the stenosed orifice does not increase in size while the growth of the heart continues. Such cases seldom reach the age of 40. Broadbent stated that the average age at death was 33 for males and 37 for females. The lesion of stenosis tends to a greater stress in the pulmonary vessels than does regurgitation, in consequence of which the left auricle and right ventricle are subjected to a greater strain, and therefore they are more likely to break in the compensation at an earlier period. As the stenosis becomes more extreme, owing to the small volume of blood ejected into the arterial system, the general nutrition becomes very defective, and at times there may be considerable pallor, as distinguished from the more 


\section{DISEASES OF THE HEART}

characteristic mitral facies. An unfavourable feature of these cases is the development of catarrh of the bronchi, and the more extensively the finer bronchi are involved and the more diffusely the process has extended, the worse will be the prognosis.

Because mitral stenosis is particularly common among women, one is more often consulted about matrimony in connection with this cardiac lesion than with any other. It is generally said that a woman's health will be injured should she become a mother, and lactation will have a still further prejudicial effect. One should not, however, be too absolute in statements of this kind; several cases have come before me which seem to have passed through the period of pregnancy and lactation with the minimum of discomfort. Thus (I) a woman, aged 24, came up to me at the Hospital, suffering from mitral stenosis and regurgitation. She had had rheumatic fever at the age of $\mathrm{I} 2$, and her mother had suffered from it four times, palpitation of the heart and dyspnoea were severe. She improved very much under treatment, and compensation was restored. I did not see her again till 5 years later, when she came up to the Hospital at my request, and I found that she had married 3 years previously, and had given birth to a child which she had nursed for 13 months. The physical signs were unchanged, but she had no cardiac 
symptoms. (2) A woman, aged 22, with mitral stenosis and regurgitation improved a good deal while an in-patient at the Hospital for 6 weeks. She appeared again 4 years later, when she had been married for 18 months, had a child 7 months old, which she had nursed for 2 months; though short of breath, her general condition was distinctly better than when I had seen her 4 years previously.

Huchard records that he has had a total of 60 parturient women with cardiac lesions, who have had with impunity 6-Io pregnancies, and Dr. Poynton mentions a patient with mitral stenosis, who had passed through nineteen confinements. It is particularly during the Ist, 4 th, $5^{\text {th }}$, and 6 th months of pregnancy that the cardiac affection may become aggravated, the main danger being generally an acute congestion of the lungs. After delivery, the patient is much better, and as a rule lactation does not seem to add materially to her troubles. Though the cardiac lesion appears sometimes to cause abortion or the death of the foetus, yet the artificial induction of labour should be a very exceptional necessity.

After a careful analysis of 300 cases of pregnancy with mitral stenosis, Hicks and French came to the conclusion that the greater number of pregnancies in women with mitral stenosis, whose compensation had not previously failed, run their course as naturally 
as do the pregnancies of healthy people, and that the treatment of such cases should not be different from that of non-pregnant women with the same lesion. ${ }^{1}$

When, therefore, the cardiac lesion is well compensated, matrimony may be permitted; if there have been one or two previous breakdowns, if allowed at all, it must only be after giving full warning of possible dangers. If the patient has reached the stage of congestion of the lungs with albuminuria, then marriage is clearly quite out of the question.

With regard to the physical signs as a guide to prognosis, it is important to note carefully the 2nd sound at the apex; so long as the 2nd sound is audible at and beyond the apex, there is little or no liability to the occurrence of symptoms, and no immediate danger of a cardiac breakdown; when, however, the and sound is no longer audible at the apex, though there may still be no symptoms under ordinary conditions of life, any slight extra exertion may provoke them. There is reason for thinking that the coarseness of the praesystolic thrill is in inverse proportion to the amount of obstruction at the mitral orifice. The disappearance of the praesystolic murmur and the substitution for it of a mid-diastolic or early diastolic murmur is an unfavourable sign, indicating, as it does, a commencing

${ }^{1}$ Guy's Hospital Reports, 1906. 
failure of compensation. The accentuation of the second sound in the pulmonary area is important to note, for, as it diminishes in intensity, we must recognise the failing of the right ventricle. Speaking generally, in all valvular lesions, weak and soft murmurs give a less favourable prognosis than loud and coarse ones, because the former indicate cardiac weakness, which is the most serious danger. Attacks of syncope in the case of women with mitral disease are, as a rule, of less serious import than one might suppose, being often due to some morbid condition of the nervous system.

Less common are the cases of stenosis of the mitral valve connected with arterio-sclerosis, and they necessarily have a less favourable prognosis than the form we have just been discussing, because the lesion is progressive. These cases are not always easy to diagnose. Though the patient may be suffering from breathlessness, palpitation, and other functional troubles, the physical signs are often by no means obvious; in particular, the reduplication of the and sound at the base will be generally absent in this form of mitral stenosis, because since the blood-pressure is raised in the pulmonary circulation, on account of the stenosis of the mitral valve and also in the aorta, owing to the arterio-sclerosis, the two sounds will be approximately equal, so that there will be no reduplication ; 
then, too, the tachycardia which is frequent in these cases causes the disappearance of the physical signs ; but, as Huchard points out, if the tension in the aorta is relaxed by rest, diet and eliminant treatment, the reduplication of the and sound at the base may again be audible, though in a feeble degree; similarly, after the heart beat has been slowed by rest and cardiac tonics, the praesystolic murmur will reappear. In these cases the dyspnoea is often particularly distressing, and sometimes they die suddenly from angina pectoris. Although the combination of narrowed mitral valve with arteriosclerosis diminishes the physical signs, it leaves the functional troubles unaffected; in fact, the very diminution of the physical signs of the one lesion increases the functional troubles of the other. This combination easily passes unperceived, and the therapeutic indications are thus unrecognised. Thrombosis is common in this form of mitral stencsis, whereas embolism is the characteristic of the endocarditic form, giving rise, if pulmonary, to infarcts and a localised pneumonia, while, if cerebral, causing hemiplegia. Cardiac arrhythmia, which is not so common in the pure form of mitral stenosis, occurs frequently in these arterio-sclerotic cases, owing to the degeneration of the myocardium and the fact that the heart has to struggle against hypertension in the systemic as well as in the pulmonary circulation. 
Treatment.-The general lines of treatment do not differ materially from those laid down for other valvular lesions ; it is always a question of estimating the strength of the heart for doing its daily work and considering how far this may be reduced, and what amount of reserve power there may be in the heart which can be evoked by a stimulus.

With regard to drugs, it has been said by Broadbent that it is best not to give digitalis in cases of mitral stenosis. This, in my opinion, is rather too absolute a statement; true it is that the striking results from digitalis, which we see in cases of mitral regurgitation, do not appear in the cases of mitral stenosis, partly because oedema is not so characteristic a feature of the latter, but certainly the general tonic effect upon the cardiac muscle has seemed to me to be no less useful. On the whole, it is in this lesion that we obtain the best effects of digitalis in small doses. Huchard speaks of mitral stenosis of cardiac origin as the only lesion which indicates the systematic administration of digitalis, even during the period of compensation. Small abstractions of blood will often be more useful in mitral stenosis than in regurgitation, particularly in order to combat the dyspnoea, which is the most characteristic symptom of this lesion; indeed, without a well-pronounced dyspnoea, one may even doubt the diagnosis. Thus in the case of Flint's 
murmur, associated with aortic regurgitation, where there is no true stenosis of the mitral valve there is also no dyspnoea, as aortic regurgitation of endocarditic origin causes the least dyspnoea of all the valvular lesions. When mitral stenosis is of arteriosclerotic, as opposed to endocarditic, origin, the line of treatment must be largely dietetic, and consists specially in the avoidance of over much nitrogenous food and all uric acid producers, while employing drugs which lower arterial tension. Digitalis can rarely be employed to advantage in this form of the lesion, as it has been well expressed by Huchard-“'le travail du cœur n'a pas besoin d'être toujours renforcé mais allégé; ce n'est pas le cœur central que doit viser la Therapeutique, c'est le cœur périphérique. Si vous voulez donner plus de force au cœur central, il faut alléger son travail en cherchant à détendre le cœur périphérique."

On the other hand, it is in the cases of mitral stenosis of rheumatic origin, in which auricular fibrillation occurs, that digitalis gives its most striking and constant results. Indeed, the researches of Dr. Mackenzie and Professor Cushny have gone far to prove that the reputation of digitalis has been largely acquired from its undoubted effectiveness in these cases, in which the pulse is disorderly both in force and frequency. Digitalis is here thought to act in auricular fibrillation by protecting the ven- 
tricle against excessive stimulation from the auricle by an inhibition of conduction in the bundle of His.

Tricuspid Stenosis.-This is a decidedly rare affection of the valves, and is but seldom diagnosed, owing to the fact that it is usually associated with mitral stenosis or some other valvular lesion. Like mitral stenosis, too, it is much more common in women than in men. Among I73 cases mentioned by Babcock, pure stenosis of the tricuspid valve, unaccompanied by any other valvular lesion, was only found in $\mathrm{I} 2$ instances. Such cases as I have seen have been always associated with mitral stenosis. As a rule, they are characterised by a considerable amount of cyanosis, upon which little effect is produced by digitalis, which is so powerful an agent in the case of mitral stenosis. Also dropsy supervenes early in these cases, whereas in mitral stenosis it is a comparatively late symptom. These patients are specially liable to hydro-thorax, owing to the obstruction to the vena azygos. Sir James Barr regards tricuspid stenosis, when associated with mitral stenosis, as a conservative lesion, saving the heart and lungs from many strains to which they would otherwise have been subjected if the mitral lesion had existed alone.

The Prognosis is always serious; in fact, it has been said by some to be the most serious of all the 
valvular lesions. When compensation begins to fail, there is small likelihood of restoring it : death comes usually from gradual cardiac exhaustion, but sudden death has been observed.

Treatment would not be different from that of mitral stenosis.

Tricuspid Regurgitation.-This lesion when functional, i.e. when due to the dilatation of the right ventricle, which admits of a reflux of blood into the right auricle, is one of the most common cardiac conditions, appearing as it does in the terminal stages of many forms of heart disease. However, as an organic lesion of the valves caused by rheumatism or other acute disease, it is most distinctly rare; more common perhaps is some thickening and contraction of the valves from chronic inflammation produced by the irritation to which the protracted strain in the pulmonary circulation gives rise.

Prognosis.-An organic affection of the tricuspid valve causing regurgitation may remain compensated for a long time, i.e. 8-1o years; but the outlook is always serious, for it is seldom unaccompanied by disease elsewhere in the heart, and any weakness of the right ventricle is at once followed by symptoms of heart failure. Gradually, however, the right auricle dilates, and the ventricle itself loses its contractile energy; the patient becomes dyspnoeic, even when he is making no movement. An 
essential feature of the weakness of the right heart is the early appearance of ascites, which may assume very considerable dimensions; puncture is only a palliative measure, for the fluid reappears with astonishing rapidity. Cerebral functions are confused, there are severe headaches, slight delirium and hallucinations. In the case where the regurgitation is functional, depending as it does on mitral lesions or affections of the myocardium, then the compensation can be restored over and over again, but a slight extra exertion or departure from the prescribed régime will at once reproduce the ventricular dilatation. The mere fact that there is insufficiency of the tricuspid valve shows that in these cases there is a high degree of cardiac weakness ; this condition may, no doubt, be improved for a time, and then its consequences will disappear, and this is particularly possible when the condition is due to bronchial catarrh, which admits of being cured.

There is no mode of death peculiar to tricuspid insufficiency per se; it generally results from oedema of the lungs, pressure effects of the dropsy, or to general cardiac exhaustion due to malnutrition.

In cases of primary tricuspid insufficiency due to endocarditis, the right ventricle is found less enlarged than when regurgitation takes place as a result of ventricular dilatation. 


\section{CHAPTER IV.}

\section{MYOCARDITIS.}

Prognosis in Myocarditis.-As far back as Laennec it had been realised that the condition of the cardiac muscle was the key to cardiac pathology and, he might have added, to the prognosis of heart disease. Stokes, too, may be quoted as saying " it is in the vital and anatomical conditions of the muscular fibres that we find the key of cardiac pathology; for, no matter what the affection may be, its symptoms mainly depend on the strength or the weakness, the irritability or the paralysis, the anatomic health or disease of the cardiac muscle." The improvement, however, in auscultation and percussion drew men's minds away from the study of the cardiac muscle to the various mechanical lesions of the valves of the heart; and yet whatever these lesions might be, the fact remains that it is the state of the heart muscle which is the arbiter of the situation. When the muscle of the heart has undergone degeneration even the most favourable valvular lesions, e.g. aortic 
stenosis and mitral regurgitation, must receive a bad prognosis, while with the muscle tissue sound and strong even aortic regurgitation and mitral stenosis may obtain a better outlook.

The great frequency of myocarditis as the cause of heart disease will be manifest if we realise that the largest number of persons who begin to exhibit signs of cardio-vascular disturbance are not suffering from valvular disease at all; clinically they simply present evidence of failing circulation with perhaps some enlargement of the heart and more or less thickening of the arteries. Post-mortem examination, however, would seem to show that various clinical pictures result from one and the same pathological change. The term myocarditis implies the anatomical conditions known as fibrosis and fatty degeneration. Owing to the indefinite character of the physical signs and the vagueness of the symptoms, this disease may not be so often diagnosed, but probably there are few cases of advanced heart disease, whatever may be its origin, which do not manifest some evidence of a chronically inflamed or degenerated cardiac muscle.

Roughly speaking, we may describe the physical signs of myocardial incompetence somewhat as follows: pulse more or less accelerated, blood pressure high (I60-200 Hg. Riva Rocci), the radial arteries roll under the fingers but are not necessarily 
sclerotic, there may be some puffiness or pitting of the ankles. Deep-seated and superficial cardiac dulness shows some increase in all directions but chiefly to the left, the outline of dulness is apt to be quadrangular, indicating general enlargement. The heart sounds are somewhat enfeebled, especially the first sound at the apex, which may be accompanied by a soft blowing murmur; the pulmonic second sound is often accentuated and the aortic second sound is loud and ringing, owing to the high blood pressure in the systemic circulation. The lungs are resonant, but at the posterior bases the râles of chronic bronchitis or hypostatic congestion may be heard and there may be some small amount of fluid in the right pleural cavity ; the liver is usually enlarged, as shown both by palpation and percussion; the urine is diminished in quantity, of high specific gravity, and may contain some albumen and granular casts. Often, however, the physical signs are extremely indefinite, amounting to little more than a diminution of the force of the cardiac impulse against the chest wall, feebleness of the heart sounds, and particularly a lessening of the muscular element in the first sound of the heart.

Now, there is a group of cases known as " latent," which furnish most of the instances of sudden and unexpected death about which we hear so much, but as physicians see comparatively little, because, as a 
rule, such patients often seem to be in fairly good health. Generally speaking they are middle-aged or elderly and apparently robust men, and their death is due to cardiac paralysis or sudden heart failure. A careful investigation, however, of the past history of such cases will usually show that the patient had not been perfectly well, but had suffered from symptoms which were attributed to indigestion, or thought to be functional. Had such cases been examined by a skilled observer they would probably have disclosed some of the signs pointing to chronic myocarditis. In this connection it is useful to observe the effect of exercise which increases the pain, dyspnoea and palpitation when the myocardium is degenerated, but has little immediate influence on a functional condition.

In another group of cases the symptoms of cardiac inadequacy are more or less conspicuous, e.g. dizziness, which is often the first symptom to attract attention, or breathlessness on exertion, associated with a sensation of weight or fulness in the praecordium, or there may be a dull ache or pain in the upper cardiac region whenever the patient walks at more than a most moderate pace. Again, the main symptom which brings the patient to the physician may be palpitation, and sometimes the patient, owing to this sensation, cannot lie on the left side, or it may be breathlessness, particularly at night, which troubles 
him most. The seat of the degenerative changes may be in the septum, involving the co-ordinating centre, which is essential to life and the degeneration of which may bring about sudden death at any moment. On the other hand, there may be a condition of hypertrophy and dilatation of the left ventricle, but with no subjective symptoms as the hypertrophy has been sufficient to enable the heart to do its work. Gradually the degenerative process saps insidiously the strength of the hypertrophied left ventricle till it becomes incapable of withstanding high intraventricular blood pressure, when suddenly, owing to the inhibitory influence of an unexpected emotion, an unwonted or hasty physical effort, a hearty meal, etc., blood pressure within the degenerated ventricle is raised to an insupportable degree and the heart stops in diastole. In quite old people, such a sudden death is hardly a matter of surprise, and a careful examination would probably have revealed some signs of general cardiac hypertrophy, as evidenced by some increase in the pulse tension, slight thickening of the arterial coats and a ringing second sound in the aortic area together with some amount of breathlessness on exertion.

Still, when all is said and done, it must be confessed that some quite serious cases of myocarditis may present no symptoms, while the physical signs are too indefinite to be relied upon. We are not without 
hope, however, that the electrocardiograph may prove as useful in the future for gauging myocardial lesions as the stethoscope has been in connection with valvular affections.

To determine the prognosis in any given case of chronic myocarditis must always be a problem of very great difficulty. Although this is the disease of the heart in which sudden death most commonly occurs, more so certainly than is the case with aortic regurgitation, when indeed sudden death is often caused by virtue of the myocardial degeneration, yet it would be rash in any given instance to predict sudden death. It is more likely to occur in cases of fatty than of fibroid degeneration. Of course, if one finds hypertrophy of the heart the predominant feature of a case, while the symptoms of cardiac inadequacy are but slight, one is justified in hoping that rational treatment will preserve the heart from any serious degree of incompetence provided that it is not overtaxed. Persistent arrhythmia is often said to be of serious import and so it may be, but it is usually connected with degeneration of the auricles, constituting what is now known as " auricular fibrillation," giving rise to the "pulsus irregularis perpetuus." This condition is not incompatible with vigorous health for a long time, and is not so serious a matter as is degeneration of the left ventricle, for the auricles are not essential to the circulation of 
the blood, being in the nature of temporary reservoirs which contain the blood flowing to the heart while the ventricles are in systole. Leyden said that, as a rule, irregularity in a case of heart disease has no special effect upon the prognosis; he had, moreover, observed many persons who had suffered their whole life long from irregular pulse. On the other hand, a pulse which is regular but habitually accelerated should be regarded with apprehension, especially when accompanied with fainting attacks or slight dyspnoea on exertion. In any form of tachycardia the diastole is shortened so that the ventricles of the heart must eventually suffer. Still, auricular fibrillation is often the beginning of cardiac failure, and Dr. Lewis thinks that few patients survive its onset for more than ten years. The pulsus alternans (a large beat alternating with a small one), ${ }^{1}$ to which Dr. J. Mackenzie has drawn attention, is always of a sinister significance, indicating, as it does, depressed contractility ; it is, however, not a common sign, yet it may be revealed by the sphygmograph when imperceptible to the finger. Dr. Romberg regards it as a rare phenomenon. ${ }^{2}$ Dr. Mackenzie considers that it implies an advanced condition of cardiac exhaustion. Dr. Vaquez too,

${ }^{1}$ Hering holds the theory that in the weak beats only a part of the one ventricle contracts, the remainder lying inactive.

${ }^{2}$ Romberg, Lehrbuch der Krankheiten des Herzens, p. 63. 
says that this is the only irregularity of the heart which, by its mere presence and independently of any circumstances accompanying it, gives a most unfavourable prognosis, indicating as it does the approaching loss of myocardial activity. ${ }^{1}$

Sclerotic changes in the kidneys, lungs or liver must always add to the gravity of the prognosis, since an additional strain is thus added to the diseased heart; in particular, when myocardial incompetence is associated with chronic nephritis the outlook must necessarily be serious, and when in this connection the gallop rhythm develops the end is seldom far off, for this indicates a degree of strain on the ventricular wall which must inevitably yield in time. Persistent cough with râles over the bases of the lung indicate that the left ventricle is losing its tonicity, while dyspeptic symptoms, enlargement of the liver, slight pitting of the ankles, suggest weakness of the right ventricle.

Angina pectoris, which will be discussed later on, has always been of grave significance, as it implies in most cases some derangement of the coronary circulation which generally carries with it the possibility of sudden death. It is indeed the sclerosis of the coronary vessels which is the chief cause of chronic changes in the myocardium, because an adequate supply of blood to the heart is thus interfered

${ }^{1}$ Vaquez, Les Arythmies, p. 400. 
with, so that the nutrition of the myocardium is directly impaired. Valvular lesions, doubtless, may give rise to degenerative changes in course of time and this is particularly the case with stenosis of the aortic or mitral valves, for in these lesions the amount of blood sent into the aorta at each systole is lessened so that the supply of blood to the coronary arteries is diminished, while in the case of mitral stenosis the stasis which is induced in the right heart obstructs the adequate flow from the coronary veins and consequently there is a defective removal of waste products. Syncopal attacks are always of grave significance and Cheyne-Stokes' respiration indicates that the end is near. A heart affected by myocarditis may perform its work fairly well so long as no additional burden is placed upon it, but any acute infectious illness and particularly influenza may cause a fatal weakening of the muscle wall, while, of course, an attack of acute bronchitis or pneumonia must be viewed with the gravest anxiety. Syncopal attacks must be regarded as serious, owing to the danger of sudden death from asystolism in such an attack. After all, perhaps the most important factors in the prognosis are not so much the physical signs, which have been mentioned above, as the age, temperament, state of general nutrition, presence or absence of general obesity, habits and mode of life of the patient. Much will depend on 
how far suitable treatment can be carried out, at least on its negative side, such as refraining from alcohol, tobacco, strong tea and coffee and the possibility of being able to give up hard work. Clearly a man who can select his place of residence and spend the winter in a mild, dry climate, is likely, caeteris paribus, to have a longer life than one who is obliged to work for his daily bread.

Treatment.-We must first consider what may be done in the way of prevention before any marked symptoms of cardiac insufficiency have made their appearance. In modern life particularly, there are many habits and conditions which are most unfavourable in this disease, and it is mainly by modifying them that we can hope to assist our patients. In the first place anything that puts a strain upon the heart must be detrimental to it. As a man advances in middle age he fails to realise that often he cannot do the same as in his youthful prime, and with any evidence of approaching cardiac insufficiency he must abandon hard physical labour, whether undertaken as a means of gaining his livelihood or for recreation. Not only is hard physical work to be deprecated, but the continued stress, strain and anxiety of a worrying business life. Here it is hardly possible to lay down rules, so much is a matter of temperament ; one man accepts with ease responsibilities which to another are a constant source of fret and trouble. 
Often if the case is entered into with care and insight, without, however, the elaboration of Freud's Psychoanalysis, the physician may discover some secret source of mental or emotional worry which is the determining cause of the myocardial breakdown, it may be over domestic, financial or business matters. These are the cases in which the physician can do so much not by prescriptions, but by timely advice, helping the patient to realise that his existing kind of life cannot with prudence be continued, while an entirely satisfactory and interesting life may be led at a lower level of physical and psychical activity.

Climate.-Nearly all those who suffer from cardiac disease do better if they can pass the winter in the South; they should avoid going out after sunset. Speaking generally, high altitudes are unfavourable, because the lowering of atmospheric pressure has a tendency to raise the arterial tension, which in the cases of cardio-arterial origin is already too high. These patients at high elevations readily get palpitations, suffer from sleeplessness and a condition of nervous erethism and at times become dyspnoeic. From $2500-4000 \mathrm{ft}$. should be the outside limit for a prolonged stay.

Diet.-Many of these patients habitually eat and drink too much and require to be put on a much more moderate diet, so that as little strain as possible 
shall be laid upon their heart, kidneys and bloodvessels. The amount of nitrogenous food must be definitely restricted; without indulging in any theories about uric acid poisoning, there is little doubt that the nitrogenous extractives tend to raise the blood pressure, and as such are distinctly harmful: one meat meal a day ought to be ample. Of course it is necessary to consider the patient's digestive powers, and to remember that carbohydrates may, as a rule, give rise to more difficulties of digestion than do proteids, and one would naturally wish to avoid the intestinal fermentation which is so readily set up by carbohydrates. In particular, flesh foods, except when taken in strict moderation, strong stock soups and broths must be forbidden owing to their extractives which stimulate the heart's action unnecessarily ; again, fried dishes are unwholesome, because of the fatty acids which they contain. Restriction of fluid is nearly always advisable, because copious draughts of water increase the labour of the heart by distending the stomach and abdominal vessels ; it is well therefore not to allow more than ro ounces with each meal.

Alcohol, strong tea and coffee are all objectionable, in that they all tend to excite the heart, and by putting unnecessary labour upon it, they endanger the integrity of the myocardium. Still one should not be too absolute in forbidding alcohol in the case 
of a man who has all his life been accustomed to it, for not only may its absence give rise to difficulties of digestion, but may cause him a certain amount of irritation and discomfort which will be more harmful to his myocardium than alcohol in strict moderation with meals, which in any case is all that should be permitted. Much depends on whether the alcohol seems to have an exciting effect upon the heart, and so to call forth an increased amount of work.

Tobacco.-In the case of a man who has always smoked from his youth up it would be unwise to cut off tobacco absolutely, but these patients must certainly avoid strong Havana cigars, which increase arterial tension, and much cigarette smoking, which is so often accompanied by inhaling, and in general submit to the rules of moderation dictated alike by their physician and by common-sense.

In all these matters of diet, it is a mistake to be too precise, remembering that men's digestive systems are as diverse as their minds, and it is well in the dietetic treatment of heart disease to apply the legal maxim of de minimis non curat (Medicina).

Tight Clothing about the abdomen, specially in the case of women, should be avoided, for by exercising pressure upon the abdomen it tends to raise the blood pressure through the action of the splanchnics ; it is on this account that deep massage may be harmful to patients with chronic myocarditis. 
Medical Gymnastics are useful in this early stage, prior to actual cardiac incompetence, and they are particularly helpful in the case of the obese. Such people are generally leading a sedentary life, sitting at their desks for hours together, so that the heart is deprived of the aid to the venous circulation which is furnished by muscular exercise and deepened respiration, while it has to drive the blood onwards against the impediment caused by the intraabdominal veins. Of all the various suggested exercises the breathing exercises are the best at this stage and not the so-called "resistance" exercises.

The object of all these artificial exercises and of golf or Oertel's hill climbing is to ease the work of the heart, and whenever they give rise to palpitation or actual dyspnoea we may be sure that the myocardium is being overtaxed, and not lightened of its labours. Generally speaking, all forms of muscular exercise may be made beneficial which promote easier breathing and a more active circulation without great fatigue. On the other hand, whatever produces dyspnoea, palpitation or a sense of fulness and discomfort in the praecordium is dangerous to persons who show high blood pressure or breathlessness. As a rule, walking on the level or up slightly rising ground is much to be recommended. Riding also is beneficial for those who are accustomed to 
ride. One should, of course, avoid walking soon after meals.

At this stage there is not much to be said about drugs, as they are usually best avoided; at the same time when hypertension is a marked feature it may be well to employ some vaso-dilator such as sodium nitrite, nitroglycerine or erythrol tetranitrate. There is no doubt that the occasional use of a blue pill, and some saline cathartic, preferably Glauber's salts, is most useful ; the patient may say that he is not at all constipated and does not want this eliminant treatment, but to remove the injurious toxines from the intestinal tract of these patients who are often large eaters is most beneficial, and sometimes the blood pressure will fall after this purgation.

The Stage of Incompetence.-In chronic myocarditis this stage often begins most insidiously, and the earliest signs are frequently some increase in the pulse rate and a certain amount of palpitation, indicating that the heart is getting overworked. And here a somewhat different policy must be adopted. There is now no hope of restoring the heart to a condition of health, it is merely a question of staving off the evil day. Of course individual cases vary enormously; while some react well to treatment and, after a short period of rest, combined with free purgation and cardiac tonics, regain something of their pristine vigour; others gradually go 
from bad to worse, sinking into the condition of the chronic invalid. The cases associated with nephritis are particularly bad, the hypertension which may at first be enormous is gradually succeeded by a state of hypotension, and then the patient's doom is sealed.

Rest.-If the heart is unequal to the demands made upon it, obviously those demands must be lessened ; thus, if an individual suffers from dyspnoea on effort, he must not make the effort; if palpitation seems to come on with very slight provocation it is best to enjoin complete rest. When the left ventricle is greatly dilated and fatty, which condition, under the strain of physical exertion, predisposes to sudden diastolic arrest, then the recumbent position should be absolutely insisted upon. Sometimes the paroxysms of dyspnoea are so distressing that the patients say they cannot remain in bed; for these it is best to secure the necessary repose by the hypodermic administration of morphine.

After a time, rest may be supplemented by massage and resistance exercises, but the patient must realise the importance of not suddenly rising to the erect posture, for a great strain is thus put upon the weakened cardiac muscle. Changes of posture must be made slowly and cautiously, or sudden death may ensue.

Resistance Exercises.-These bring into play the muscular contraction and vigorous action of the 
diaphragm, together with the other respiratory muscles which assist the circulation. The movements must be executed with gentleness and precision, so as to help the heart, and not to put any additional labour upon it. At first the exercises may be given while the patient still lies in bed; as he improves he may sit up during his resisted movements; while only after the heart's strength has gained considerably can daily treatment be taken in the standing position. At this stage, those exercises which constrict the abdomen, or involve the elevation of the arms above the patient's head, are best avoided, as they are likely to bring on dyspnoea. The aim of these exercises is to divert the blood from the heart to the extremities and thus to reduce dilatation.

Massage is most useful in cases of prolonged recumbency, as it relieves the portal hypertension and promotes the return flow of the blood; massage of the muscles diminishes the frequency of the pulse and also the arterial tension ; but the abdomen must not be massaged deeply and strongly, for this tends to raise the blood pressure, which, ex hypothesi, is already too high.

Nauheim Baths.-It is in these cases of chronic myocardial incompetence that the baths of Nauheim are specially useful, but they should not be administered as a last resort, but be begun early before marked 
dilatation has set in; an important object being to enable a heart which cannot expel all its contents, to empty itself completely. The treatment improves the nutrition of the heart as the circulation becomes more active. It is quite possible to get excellent results from these baths when artificially prepared, provided reasonable precautions are taken, and as Bad Nauheim is only open from May-October, it is almost essential to do this. The natural springs are impregnated with sodium and calcium chloride, and they are also highly charged with carbonic acid, so that they are very stimulating. It is best to begin the baths cautiously, without any carbonic acid and a moderately high temperature, i.e. $93^{\circ}-95^{\circ} \mathrm{F}$., the water containing I per cent. of sodium chloride and $\frac{1}{10}$ per cent. of calcium chloride and the bath lasting from 5-8 minutes, according to the reaction of the patient. He should avoid all movements while in the bath, and if at first he feels chilly the bath must be made warmer, or given up altogether. As a rule, old people stand a few baths of longer duration better than frequent and short-lasting baths. Gradually when the feeble and dilated heart has improved, we can then slowly increase the amount of the salts till the chloride of sodium reaches 3 per cent. and the chloride of calcium I per cent., the temperature is reduced to $87^{\circ}-85^{\circ}$, while the duration of the bath may be increased to 20 minutes and carbonic acid 
added, so that there is a more energetic stimulation, resulting from the cool, strongly saline effervescing waters. This addition of the carbonic acid, or the strombad as it is called, is by no means suitable for all cases, and should certainly not be used in the later stages of cardiac weakness. Considerable care should be exercised in this line of treatment, or it may prove injurious instead of beneficial. Such baths are contra-indicated when there is a high degree of cardiac weakness, as evidenced by dyspnoea when at rest, general weakness and considerable oedema, also in severe cases of angina, and when there is a liability to cerebral haemorrhage. In particular, one must proceed with caution where there is arterio sclerosis.

Nourishment is often extremely difficult owing to the digestive disturbances resulting from circulatory embarrassment. A dietary fairly rich in proteids may often be recommended at this stage, for articles of animal origin are less likely to give rise to flatulence than are cereals and vegetables, which are so rich in carbohydrates. Since digestion is slow and absorption less rapid than in healthy persons without hepatic and gastric stasis, it is a good rule not to administer food at very short intervals. At times patients with an unusually high pulse tension may be confined to an exclusive milk diet for a few days until the pressure has been reduced. 
Drugs.-In this form of cardiac disease digitalis may often be useful, at the same time one must have a careful regard to the state of the vessels, for, if the blood pressure is high and the vessels stiff, digitalis must be administered with great caution, as dyspnoea and palpitation may be easily increased, and in those cases which are associated with chronic nephritis it can seldom with prudence be administered at all. When the cardiac muscle is greatly damaged there will not be much response to digitalis, the effect of which will only be seen on the arterioles ; these by contracting under the influence of digitalis tend to raise the blood pressure and so increase the work of the heart, which is just what should be avoided at all costs. In these cases, if given at all, it should be in small doses, from 5-Io minims of the tincture, three times a day, combined with nitroglycerine, or gr. 2-3 of sodium iodide. As regards the different preparations of digitalis, I have found the tincture made from Park Davis \& Co.'s standardised "liquor digitalis" to be most satisfactory. The crystallised granules of digitaline (nativelle) have seemed to me specially useful when given in small doses (gr. $\frac{1}{240}$ ) over a long period.

Digalen (Cloetta) is a solution of amorphous digitoxin. It can be given intravenously and its action is then very rapid. It is further claimed for it that it does not provoke digestive disturbances, but I 
have not found this to be the case. Some few patients undoubtedly have an idiosyncracy against digitalis, but apart from this, most patients take the standardised tincture of digitalis well, and vomiting occurs quite as often if digalen is employed.

Poisoning by digitalis is shown by the pulse, which had been slowed, becoming quickened and very irregular; the blood pressure falls, the patient suffers from headache, giddiness, vomiting and fainting fits.

Strophanthus may be more helpful than digitalis in these cases of hypertension, as it does not cause contraction of the blood vessels; there is also less need to fear cumulative effects, but more often some vaso-dilator of the nitrite group will prove more suitable.

Ammonia sometimes produces a striking improvement in those patients who do not bear well drugs which slow the pulse and contract the blood vessels.

Caffeine and strychnine are excellent for sustaining flagging hearts when digitalis and strophanthus are inadmissible; both are most effective when given hypodermically, e.g. caffeine gr. $\frac{1}{2}-$ I t.d.s., strychnine gr. $\frac{1}{60}$ IV horis.

Diuretin (sodio-solicylate of theobromine) alone or in combination with digitalis infusion may be given from $3 \mathbf{i}-3$ ii per diem.

This is one of the most useful drugs for removing 
oedema, and it may be profitably continued for weeks or months.

In combating oedema cathartics are a great help and should be given so as to produce several watery stools per diem. Since the transudation of serum is constant, its removal by means of hydragogue cathartics should be accomplished daily and not merely occasionally. Magnesium Sulphate in a saturated solution is most useful, and may be given every hour in $3 \mathrm{i}$ doses till satisfactory results are obtained. Of course all these remedies may in time produce anaemia and emaciation, but it is essential to remove the venous stasis, and the other ill effects must be counteracted by simple nourishing food, iron and arsenic. It is most important to avoid constipation, because of the straining involved.

Venesection when the case is seen at the stage of profound inadequacy with excessive distension of the right heart, then depletion is of the first importance, and it is no use trying to spur the already overtaxed heart; in such conditions, the removal of 15-20 ozs. of blood may be of the greatest benefit, albeit the relief may be but temporary.

Morphine and Heroin are most useful for the distressing nocturnal attacks of dyspnoea and also for insomnia; as a rule, morphine gr. $\frac{1}{8}$, combined with atrophine gr. $\frac{1}{200}$, will be sufficient. 


\section{CHAPTER V.}

ANGINA PECTORIS.

Angina Pectoris.-Owing to the intensity and painful nature of the symptoms, its sudden onset and frequent dramatic termination in death, it has from the time of its first description by Heberden continued to exercise an extraordinary fascination over the minds of all practising clinical physicians. Of late years we have come to know much more of its pathology, and there is now an almost general agreement that it is associated with some disease of the coronary circulation, by which the blood irrigation of the myocardium is impaired, the myocardium apparently exhibiting a high degree of sensitiveness to a deficient supply of oxygen. The immediate causes, too, of angina pectoris have now been classified, so that we are in a better position for dealing with the treatment and prognosis.

The classical instance of Dr. Arnold teaches us how the first attack of angina may also prove to be the last and fatal one, even though occurring at a 
comparatively early age (47); on the other hand, a period of more than 20 years may elapse between the first attack and the final end, during which period there may have been a number of attacks at intervals of varying frequency.

The first attack of angina nearly always occurs after exertion, though later on the attacks may supervene with but the slightest provocation, or even at night during complete repose, in which case it is most often due to some digestive disturbance.

Angina pectoris is one of the conditions associated with sudden death, so that the friends of the patient should be warned of the possibility of a fatal termination. To give any very definite prognosis is almost impossible, "the cardinal fact about the prognosis being its uncertainty" (Walshe), there are instances of men continuing to have attacks of angina off and on for 20 years, on the other hand, there are cases in which death has occurred in I0-I5 days after the first attack. As a rule, the more severe the seizures the greater is the danger of death; the more easily the paroxysms are evoked the more extensive must be the coronary obstruction, and consequently the more serious the complaint. When the attacks occur without any obvious provocation, and particularly at night when the patient is at rest, the prognosis is grave. The outlook, however, is better if the attacks become less severe, and the intervals 
between them longer; also when they only come on after exertion, excitement or indigestion, especially when there is a high tension pulse, they may be postponed indefinitely by suitable treatment. Much will depend on the patient himself and how far he can be induced to make radical changes in his existing mode of life, and live on what may seem to him an altogether lower level of activity, while at the same time practising some degree of abstemiousness as regards food, alcohol, tea, coffee and tobacco. It has been well said, that a severe attack of angina may save a man's life, for it may frighten him into sobriety.

Many cases of angina have been found to result from lues, and when angina occurs in a patient under 45 , lues should be always suspected. These cases have a favourable prognosis, for they usually respond very well to iodides. During the attack itself, CheyneStokes' respiration and a slow, irregular pulse are of evil omen.

Pulsus alternans when observed is regarded by Dr. Mackenzie and Dr. Lewis as of most sinister prognostic significance.

One should never be induced to give a favourable prognosis from the fact that one has failed to detect evidence of any organic disease; in most cases, however, some morbid change in the aorta or heart or both will reveal itself. Balfour says that he 
never met with an instance of angina in which signs of dilatation of the heart were not present.

There is a form of angina in which there may be sclerosis of the coronary arteries and consequent functional ischaemia, but vaso-motor factors do not share in the production of the symptoms, the pain being directly dependent upon exercise. This form of angina has a more serious prognosis than that which occurs in a patient suffering from general arterial sclerosis and vaso-motor spasms. Though it is rare to find a case of angina before the age of 45 , yet when associated with aortic disease it may occur in early adult life and run a protracted course; when the pulse is soft, and the heart normal in dimensions with imperceptible impulse and weak sounds, then the prognosis is most serious. Old people seem to tolerate serious lesions of the myocardium better than younger persons.

Treatment.-(I) The actual paroxysm. If the patient has any warning it is well to place him in a quiet well-ventilated room with the window open. The sitting posture is usually most comfortable, the clothes about the neck and chest should be loosened. Sucking ice and cold applications to the praecordia generally afford the patient some relief.

The introduction, by Sir Lauder Brunton, of nitrite of amyl has been undoubtedly the greatest boon to these patients. It is best to give a few drops 
of nitrite of amyl by inhalation or to drop upon the tongue $\mathrm{m} i$ of a $I$ per cent. solution of nitroglycerine. As a rule this remedy gives prompt relief by relaxing the arterial spasm which is so often the immediate cause of the pain. When the phenomena of vascular spasms are absent, or when relief does not quickly follow the use of nitrites, it is better to have recourse to a hypodermic injection of morphia (gr. $\frac{1}{4}-\frac{1}{3}$ ) as rapid relief from the pain is so essential.

In milder cases, much relief may be given by spiritus ammon. aromat., Hoffmann's anodyne, camphor or some brandy or whisky in hot water, but the latter, needless to say, are dangerous remedies in a chronic complaint. These medicinal measures may be supplemented, specially at night, by heat in the form of hot bottles to the extremities, praecordia, epigastrium or between the shoulders. Since nitrites increase the frequency of the heart's action, they may be a source of distress, so that we should employ them cautiously when the angina is accompanied by a frequent pulse. One drawback to these remedies is that they are so efficacious, at least temporarily, that the patient is tempted to do things which are prejudicial to his heart, knowing that he is possessed of so simple and easy a means of cutting short an attack.

In the Intervals of the Paroxysms.-The main fact to realise in angina pectoris is that the heart is 
unequal to its work ; it is the heart which is always at fault, but excessive peripheral resistance is often an important factor, particularly in the production of pain. Hence in treating a case of angina we must first consider whether there is any arterio-capillary obstruction which can be removed, and consequently we must adopt all the methods, both dietetic and medicinal, which have been previously detailed for combating high arterial tension. In cases of gouty angina, colchicum with a mercurial aperient will be found eminently satisfactory. Sometimes there is no excess of tension in the arteries, their walls being in a state of degeneration, while the walls of the heart also are weak ; in such cases we must use mercurial aperients more sparingly, keeping the bowels open with an aloetic pill, liquorice or cascara. In these cases where eliminant treatment is not so obviously demanded, we may find that great relief is obtained by the employment of arsenic and phosphorus. Iodide of potassium is always useful in combating the pain, and I have found the combination of that drug with arsenic to be particularly effective. Recently a case of mine-a woman with aortic disease due to lues was having very frequent attacks of angina; though immediate and quite definite relief was obtained in the attack from nitroglycerine, nothing seemed to avert the frequency of the attacks. I was giving her iodide of potassium gr. $\mathrm{x}$ three times 
a day without much improvement. I then added a small quantity of tinct. opii. to each dose, and though this rendered the paroxysms less severe, they did not become less frequent. Latterly I have substituted liq. arsenicalis $m$ iii for the tinct. opii., which together with the iodide of potassium seems to have the most excellent results, both in reducing the frequency as well as the severity of the attacks. The great thing is, of course, so to regulate the patient's life as to minimise the possibility of an attack. Thus he should be cautioned against walking immediately after a meal, or walking against a wind, or uphill, except with the greatest circumspection. In particular, he should avoid exposure to cold and inclement weather, and not be insufficiently clad or attempt to carry heavy hand-bags and parcels. To avoid fits of passion, immoderate coitus, overeating, the free indulgence in tobacco and alcohol goes without saying. Resistance exercises are particularly useful in cases of angina and so, too, is the careful use of the Nauheim bath.

Pseudo Angina or Angina Vaso-Motoria.-That this condition is a functional affection of the heart there can be no sort of doubt, differing in all essentials toto caelo from the more serious malady which we have just been discussing. Superficially, there is the resemblance of the sudden pain in the praecordia, often shooting down the left arm, together 
with a sense of constriction and want of breath; at times I have met with cases in which, following on the pain, there has been a prolonged faint, or the patient has passed into a cataleptic state, apparently, though not actually unconscious. The pain may be severe and prolonged, but it is not certainly so agonising as that of angina proper. Though it may be accompanied by a sense of constriction, yet it is more usual to find patients complaining of a sensation of fulness and pressure in the cardiac region. It is almost confined to the female sex, and occurs at an age much younger than that of true angina. I have spoken of it as a functional condition, because it is unassociated with any recognised pathological lesion of the myocardium, coronary arteries or aorta.

The important difference between true and false angina has been well and briefly expressed by saying that " in true angina there is some condition within the heart which initiates the stimulus that is sent to the nerve centres, whereas in false angina the starting point of the painful attack is not the heart, but some peripheral or visceral nerve, most commonly one of the intercostals." The attack lasts longer than that of true angina, it may be I-2 hours, and its departure is apt to leave the patient weak and exhausted; sometimes it may abate suddenly or may terminate in an attack of violent palpitations. The prognosis is, as a rule, entirely favourable; 
instances of death in an attack are not unknown, but they are very rare. On the other hand, the symptoms may prove very refractory to treatment and, if the underlying neurosis is not judiciously handled, may drag on indefinitely, so that the patient becomes practically a chronic invalid. This, however, is the exception, and most cases get well. I have been impressed by the frequency with which these symptoms of pseudo angina have started from a quite definite emotional disturbance in an otherwise healthy individual ; in these cases the symptoms have been severe and even alarming, but the ultimate outlook has been quite favourable.

Treatment.-As in the case of true angina when there is obviously arterial spasm during the attack amyl nitrite is clearly indicated; similarly, when there is no such spasm it may sometimes be necessary to administer morphia subcutaneously. When the body surface is cold it is well to apply heat to the trunk and extremities, together with ammonia or other diffusible stimulants. But the point of greatest importance is for the physician to search in the intervals for the possible causes of these attacks. Constipation should be guarded against and flatulence treated, as almost any kind of digestive disturbance may give rise to this form of angina. Attention should be paid to the clothing, so that too tight skirt bands may not increase the dragging of 
the abdominal contents upon their supports. In these cases massage is often useful. I had under my care at the hospital a very obstinate case of a school teacher who had suffered from these anginiform attacks for some years, their origin having been connected with an emotional disturbance; after failing entirely to lessen the frequency or severity of the attacks while treating her as an out-patient, although she had abundant opportunities of resting at home, I took her into the hospital and treated her with the artificial Nauheim baths and for the last two years she has been entirely free from the attacks. Often, where possible, the best remedy is a complete change of scene and circumstance for a few months. 


\section{CHAPTER VI.}

FUNCTIONAL AFFECTIONS AND HEART STRAIN.

Cardiac Neuroses. - Though it seems probable that heart disease of an organic nature has decreased of late years, perhaps owing to the earlier detection of rheumatic manifestations and their improved treatment, yet if we include under the term heart disease all the various morbid perturbations of the heart's activity, then undoubtedly the range of our conception of circulatory diseases will be greatly increased. In common with other classes of illness, the advance of civilisation, while favourable to the disappearance of the grosser types of disease, seems provocative of those minor oscillations of function, which are in many instances no less distressing to the patient, because they unfit him for the more complicated environment of modern life as effectually as do the results of organic disease. Nervous individuals are conscious of processes which in the healthy do not penetrate the sensory sphere; in fact their threshold of sensation is at a lower level. 
Palpitation.-By this is meant a distressing consciousness of the heart beat. Though often associated with tachycardia, it is by no means necessarily so connected, and the heart may be beating at the rate of 250 without the patient being aware of any uncomfortable sensation. It is quite as often a functional disturbance as the accompaniment of organic disease: Thus Laennec said " Les Palpitations sans lésions organiques sont souvent plus incommodes que les autres," and also Senac, as far back as I749, said; "Les palpitations surviennent surtout dans les maladies où il n'y a aucun vice du coeur." In fact, there is hardly any part of the body which may not at times give rise to palpitation of the heart. In most cases therefore, palpitation not being symptomatic of any organic affection of the heart, the prognosis is consequently quite favourable.

Treatment is largely a matter of realising the causes which give rise to palpitation and eliminating them, e.g. (I) tea drinking-this is one of the most fertile causes of palpitation, and in America, Bullard of Boston has described the disease of the teatasters, which is characterised by insomnia, cerebral excitement, hallucinations, and above all, palpitations; (2) coffee in excess gives rise not only to palpitations but to tremors, praecordial pain, occasional sickness, vaso-motor troubles, which consist in profuse and abundant sweats; (3) tobacco, 
which will also give rise to intermittence and irregularity of the pulse ; (4) digestive troubles, which are the most common source of palpitations ; (5) finally, there is the form which is described by Huchard as " false palpitation," in which the heart beats against a chest wall which is hyperaesthetic; owing to an intercostal neuralgia, the heart beats are felt as painful at each cardiac cycle; in such cases the treatment will not be by drugs, but by the local application of methyl chloride.

If no obvious cause can be discovered, the unpleasant symptoms can usually be removed by careful attention to the general health. In particular, it is wise to insist on regular exercise in moderation and also regular hours of sleep. The diet should be light. When, as is sometimes the case, palpitation is accompanied by high tension, it will be relieved by sodium nitrite (gr. i) with tincture of aconite ( $m v$ ) three times a day. I have generally found a combination of belladonna and bromide of sodium most useful for palliative treatment. The troublesome palpitation with which a patient often wakes up in the middle of the night may generally be avoided by a dose at bedtime of pot. bicarb. (gr. xx), sp. ammon. aromat. $3 i$, aq. menth. pip. ad. 3 f.

Sometimes at the onset of an attack of palpitation, if a few deep breaths be slowly taken, the condition may be arrested. 
Irritable Heart.-This condition was first studied by Peacock among the miners of Cornwall, who had to perform very heavy work in a cramped attitude and in a vitiated atmosphere. A similar condition in the case of soldiers during the American Civil War was investigated by $\mathrm{Da}$ Costa. Though excessive physical exertion would seem to have been the main cause of the cardiac symptoms in both cases, yet it is quite impossible to exclude other influences, such as alcohol and tobacco, while in $\mathrm{Da}$ Costa's cases there was the mental anxiety inseparable from the hardships of campaigning.

The main symptoms of an irritable heart are (I) praecordial pain, (2) rapid cardiac action; doubtless in nervous persons similar symptoms may be produced by distension of the stomach and constipation. As a rule, there are no special physical signs in this condition, so that it is often regarded too lightly; sometimes, however, there may be a systolic murmur at the apex, more often an impurity of the first sound and some dilatation of the heart.

Prognosis.-Though the condition of "Irritable Heart " is not associated with a lesion of the myocardium, it is by no means easy to be sure of this in any given case; consequently, even when the symptoms seem most clearly to have come on after over-exertion on the part of a healthy man, it is 
well to give a guarded prognosis till the progress of the case can be further watched. In most cases it would be unwise to allow the patient to resume an occupation which might involve considerable muscular exertion, but when one can feel sure that the myocardium is sound, there is no reason why recovery should not be complete, assuming the circumstances of the patient's life are otherwise suitable.

Treatment.-When the condition is acute, the patient must have complete bodily and mental rest. An ice bag to the heart will generally relieve its rapid action; mustard poultices and a hot footbath will be helpful. When the acute stage is over, advantage is derived from massage, baths and graduated exercises against resistance. Muscular exertion must be restricted for a time, and then, when resumed, carefully regulated. Alcohol and tobacco should be eschewed, while tea and coffee may only be permitted in strict moderation.

Heart Strain.-Difficult as it may often be to isolate this condition from other factors, such as alcohol and lues, yet there is undoubtedly a group of cases which owe their symptoms to mechanical strain upon the heart, and mechanical strain only. The symptoms complained of are usually those of cardiac weakness, namely shortness of breath and feelings of faintness on exertion, palpitation and 
perhaps pain. When at rest, the pulse is usually regular, though perhaps somewhat rapid, but on moderate exertion there will be definite tachycardia, and the beats may become irregular, while the cardiac impulse is forcible and tumbling. On auscultation the sounds may sometimes be louder than usual, and there is generally a short blowing systolic murmur to be heard at the apex. On careful enquiry into the history, there is no evidence of any disease likely to have caused endocarditis, but one finds that such patients have perhaps gone in heavily for athletics, or that their work has required some exceptional exertion. Many of these troubles are caused by men embarking on athletic pursuits without adequate training ; this is especially true of middle-aged men, who leave their desk and brain-work for a short holiday of long bicycle rides, or of arduous mountain climbing. In youth, no doubt, there may be less need for training, yet even in early life there may be physical signs and symptoms, if excessive and prolonged exertion is suddenly undertaken : in fact, most of these cases which have come before me have been in comparatively young men.

Professor Clifford Allbutt, out of the fulness of his experience, tells us that dilatation of the right side of the heart is an early effect of prolonged exertion, such as running, hill climbing, or steady 
rowing, but a sudden exertion puts a strain rather on the aortic area.

Prognosis is on the whole good, provided the patient can take suitable rest, give up all serious exertion for about a year, and then not indulge in any athletics without adequate training. There are, however, cases which may drift on into a condition of chronic dilatation of the heart.

The following cases illustrate the generally favourable prognosis one may reasonably give in these conditions, which do not, as a rule, require any special treatment:

(I) J. W., a man aged 29, whom I first saw in Dec., I904, complained of having suffered from shortness of breath on exertion off and on for 8-9 years. There was a short systolic murmur at the apex, rather flapping in character, while the pulse was feeble and of low tension. There was no history of rheumatism or scarlet fever, but he confessed to having done a great deal of cycling and swimming. He decided to give up these exercises for a time altogether, and now, some seven years later (IgI2), though he cycles and swims, but in strict moderation, he is quite free from symptoms, the pulse is stronger, and there is only a systolic murmur audible in the 3 rd and $4^{\text {th }}$ left spaces, which is, doubtless, of no particular importance.

(2) H. T., a man aged 24, complained of shortness 
of breath and pains at the heart in Aug., I905 The pulse was somewhat rapid and of low tension, there was a blowing systolic murmur at the apex, and signs of some dilatation of the heart. $\mathrm{He}$ gave no history of any illness, but 4 years previously he had begun to row a good deal in races ; towards the end of the 3 rd year he used to become greatly exhausted, so that he gave up rowing, and for the past year had suffered from the above-mentioned symptoms. When I saw him again (IgI2), some $6 \frac{1}{2}$ years later, he was entirely free from symptoms, and the heart sounds were normal, though the pulse was rather quick. He had given up athletic exercises, and avoids lifting heavy things; if he does so, he experiences a dull heavy pain in the heart the following day.

(3) G. M., a clerk, aged I7, was seen by me in Dec., I907, complaining of pains round the heart and slight giddiness. There was a heaving impulse, and a loud booming systolic murmur at the apex. There was no history of any previous illness of importance, but he had been working hard at gymnastics and rowing a good deal. When I saw him 4 years later, he was quite free from any symptoms, the heart sounds were normal, and the cardiac impulse no longer heaving.

(4) J. B., a man aged 24, whom I saw in June, I906, had been a diver in the Navy, and was invalided 
out of the service for "Organic heart disease." When I saw him he had no symptoms, but there was a well-marked mitral regurgitant murmur at the apex. Some $5 \frac{1}{2}$ years later (IgI2) I heard that he was in Canada doing hard work there, that he enjoyed excellent health, and had been able to insure his life. 


\section{CHAPTER VII.}

PAROXYSMAL TACHYCARDIA AND STOKESADAMS' DISEASE.

Paroxysmal Tachycardia.-Of late years this comparatively uncommon cardiac condition has been recorded with more frequency, perhaps owing to the stimulus which Dr. J. Mackenzie has given to the study of all forms of unusual cardiac rhythm. So far, however, it does not appear that the condition of paroxysmal tachycardia can be produced by any experimental procedure on the nerve supply of the heart ; it is due rather to the normal cardiac rhythm being abruptly submerged in rapid contractions of the muscle responding to a series of new, rhythmic and pathological impulses. ${ }^{1}$ These impulses are elaborated in a single focus at a point removed from the sino-auricular node where the work of cardiac contraction normally starts. The site of the abnormal focus of contraction is said to be in the auricle.

The main features of this curious symptom-complex are that the heart suddenly starts beating with

${ }^{1}$ Lewis, Clinical Disorders of the Heart Beat, p. 55. 
unusual rapidity, the rate being anything from I50 to 300 a minute, and continuing without any apparent reason for the space of a few hours, or even 2 to 3 weeks, or months, and then ceasing abruptly. The rate is unaffected by alteration of respiration or changes of posture. Sometimes the patients describe the termination as though the heart had been pushed back into its right place, at others there is a stabbing pain in the chest. Meantime the patient, though suffering some discomfort, is not usually so greatly inconvenienced as would a priori be expected, and often the sufferers from this affection are able for a time to continue at their work. The suddenness of the onset and of the termination are remarkable phenomena ; usually no valvular disease of the heart can be detected, and there is no evidence of dilatation in the intervals between the paroxysms. Another feature is that the pulse rate remains about the same both in the upright and recumbent positions; but I have had a boy under my care with the signs of mitral stenosis, whose only trouble consisted in the attacks of paroxysmal tachycardia; Dr. Rolleston has shown me a case of aortic disease of rheumatic origin in a young man who is subject to frequent attacks of paroxysmal tachycardia, and I have also recorded in the British Medical Journal (IgII) the case of a woman, the subject of this symptom-complex, who 
died in one of the attacks, and the post mortem revealed an exceptionally large patent foramen ovale; in each case, however, the organic lesion had apparently a merely accidental connection with the paroxysmal tachycardia. When cardiac murmurs are present, they usually disappear during the paroxysm of tachycardia.

Prognosis.-As regards life, this may in general be described as favourable. Professor Osler mentions ${ }^{1}$ the case of a physician in his 87 th year, who had been subject to attacks of this kind at intervals from the age of 37 , so that there is nothing incompatible with a long life in the fact that one suffers from paroxysmal tachycardia. I myself saw, not long ago, a doctor, aged 70 , who had suffered from these attacks for some years. Indeed, there seems to be a tendency for the attacks to become less frequent and less severe with advancing years. At the same time it must be realised that the attacks themselves are evidence that the heart muscle is not entirely sound, and that when an attack of this kind lasts for several days, or even weeks, there is great danger of dilatation of the heart, which may become permanent, and all the symptoms of backward pressure may supervene-pulmonary congestion, oedema of the feet, etc.-with a fatal termination, so that even with regard to life our prognosis must

${ }^{1}$ System of Medicine, Edit. vi. p. 836. 
be guarded. The case mentioned above with a large patent foramen ovale died suddenly in one of the attacks of paroxysmal tachycardia, to which she had been subject for I4 years; but such an occurrence is exceptional. The general outlook must be based on the heart's power of reaction to moderate effort in the intervals of the attacks. On the whole, if the heart does not increase in size, and the attacks are of short duration, the prognosis is good. The other question in prognosis which requires an answer is " Can the condition be cured ?" so that there shall be no recurrence of the attacks. In the present state of our knowledge a distinct negative must be returned to this query. No doubt judicious treatment in many cases reduces the frequency of the attacks, and renders them less severe, but their permanent arrest is too infrequent to justify one in holding out uncertain hopes. There is indeed a superficial analogy between this condition and epilepsy, to which Hoffmann ${ }^{1}$ has drawn attention, but in the case of epilepsy, treatment may certainly in some cases bring about a cure, but the same cannot be asserted of paroxysmal tachycardia. A practical point arises as to whether such patients should be recommended to go on with their work. In the absence of more definite knowledge as to the causation of the condition, one hardly

${ }^{1}$ Deutsches Archiv für klin. Med. B. Ixxviii. S. 39. 
seems justified in interfering with a patient's means of obtaining a livelihood, unless the attacks are becoming more prolonged, or signs of cardiac dilatation have manifested themselves in the intervals; most patients have discovered a few things which they believe bring on the attacks, and the avoidance of these is all that need be insisted upon. Speaking generally, the less frequent the attacks the longer they last. As a rule, the attacks in the case of any given patient are of about the same duration.

Treatment.-During the attack it is generally helpful to lower the head and elevate the legs. The application of an ice bag to the heart will usually afford some relief. Often patients have been able to arrest their attacks by taking ice-water or strong coffee, though I have not myself found this efficacious: more useful has been the administration of an emetic, acting on the suggestion of a patient, who found that vomiting always relieved him, but it has a depressing effect, and is not to be generally recommended. One patient of mine experienced benefit from having cold water poured over the wrists. Some relief may be obtained by making the patient press the elbows into the sides and at the same time making pressure on the abdomen; Rosenfeld claims to have cured four cases by this method. The application of a tight abdominal 
binder may often be immediately effective. Compression of the trunk of the vagus in the neck at the level of the angle of the thyroid cartilage has been said to be efficient in arresting the attack, if this is not successful, galvanization of the nerve may be tried. ${ }^{1}$ Huchard has recommended anaesthetising the skin of the neck with methyl chloride, and the application of an ice bag to the thyroid gland. Sometimes by making deep swallowing movements the inhibitory action of the vagus nerve is set in motion and the attack arrested. Drugs, during the attack, seem to be of very little use ; digitalis given in fairly large doses has had no effect in my hands upon the rapidity of the cardiac action ; occasionally I have had good results with erythrol tetranitrate, and it seems worth trying. Obviously, however, it is most difficult to estimate the value of any line of treatment in a disease which naturally terminates with such arbitrary suddenness. Anodynes are seldom required, for, though the general discomfort may be considerable, there is rarely severe pain.

In the intervals of the attacks, special attention should be paid to the digestive system, as the seizures seem often to arise in connection with some gastro-intestinal disturbance. Alcohol and tobacco should certainly be avoided, and tea only taken in strict moderation. There would seem to be no

${ }^{1}$ System of Medicine, Osler and $\mathrm{M}^{\top} \mathrm{C} \mathrm{Crae}$, vol. iv. p. 302. 
objection to the patient taking ordinary exercise, or to following his occupation, provided it is not exceptionally arduous. Dr. Lewis speaks well of the continual wearing of an abdominal belt applied before rising and omitted at bed-time. With regard to drugs, I have found some help from pot. brom. gr. $\mathrm{x}$, together with tinct. hyoscyami If three times a day, which have seemed to reduce the frequency of the attacks. "Keark block."

Stokes-Adams' Disease. - This most interesting symptom-complex has been a good deal studied of late years under the name of heart block; the discovery of the bundle of His and the researches of Dr. J. Mackenzie having thrown a good deal of light upon the disease. By heart block is meant a condition in which the rhythm of the auricle is maintained, but that of the ventricle does not follow, whereas a genuine condition of slow pulse involves both auricles and ventricles. Heart block may be produced experimentally by an impairment of the stimulus conduction from auricle to ventricle. Lesions have been found with sufficient frequency in the auriculo-ventricular bundle to justify us in regarding Stokes-Adams' disease as a genuine disease of the heart, and not of the central nervous system. The ventricle beats at a very slow rate independently of the rate of the auricles; the auricular beat being represented by pulsation of the 
jugular vein. Clinically this condition is characterised by a slow pulse, which may be anything under 40, with frequent syncopal or epileptiform attacks; in fact, when seen unexpectedly the attack may appear to be an ordinary one of epilepsy. More usually the attacks resemble petit mal seizures with slight twitching of the limbs and face, there being, however, this difference, that in StokesAdams' disease the patient always knows when he has had an attack, which is by no means always the case in petit mal. One case of mine would often wake up from his attack shouting loudly. Though the epileptiform attacks may be corrected by treatment, the condition of slow pulse remains.

Prognosis is always serious, and the obscurity of the underlying cause makes it difficult to form any definite conjecture as to the duration of life. Speaking generally, we should say that it was rare for a patient to live more than ro years when once these symptoms have declared themselves; about 5 years would be the more usual period. Professor Osler mentions the case of a patient who had only nine attacks in $\mathrm{I} 2$ years, and in the intervals enjoyed good health. The frequency and severity of the attacks are said to be some indication of the gravity of the disease. A patient of mine, aged 48 , came to me at the hospital in Oct., r9ro, having been seized suddenly with a fainting attack 4 months 
previously; the attacks were occurring with great frequency-several in a day. The pulse rate varied from 28 to 32 ; he was taken into the hospital for a month, and has not had an attack since (about a year); he has taken iron and strychnine.

As regards occupation, much the same rules will apply here as are observed in epilepsy. As far as possible a man should be allowed to continue his work, provided it is not unduly heavy, but of course he should not do anything which involves going up ladders, driving horses, or motor cars, on account of the liability to epileptiform seizures, which occur without any warning. I had a man under my care for 3 years, who was a carpenter, and during the greater part of that time he had been able to do his work satisfactorily, only taking jobs where he could be on the ground floor. Apart from the syncopal and epileptiform attacks, he had excellent health, and always looked extremely well. Eventually he died of acute pneumonia, some 8 years after the first onset of the symptoms of Stokes-Adams' disease, but unfortunately there was no post mortem. In cases which originate from lues, prompt and active treatment may bring about recovery.

Treatment.-With regard to the immediate attack, there is not much to be done, except to lower the head and elevate the legs, with a view to counteracting the anaemia of the brain; generally the 
attack is over before there is time to do much; otherwise, oxygen inhalations or injection of strychnine should be tried.

In the intervals one should treat the underlying cause, whenever that can be diagnosed. Often there is evidence of arterio-sclerosis, and the treatment of that condition will frequently stave off the attacks, or there may be arteritis of the cerebral arteries due to lues, and here the administration of mercury and iodide of potassium will be found most effective ; in fact, these are the only cases in which one can give an at all favourable prognosis. In the case of the carpenter alluded to above, in whom I could detect no underlying cause except that he had been a very heavy smoker, so that his tobacco had to be greatly cut down, a good deal of help was derived from strophanthus.

$\mathbf{R}_{\mathbf{x}}$

$\begin{array}{ll}\text { Tinct. strophanti } & m \text { vii } \\ \text { Sp. ammon. aromat. } & 3 \mathrm{f} \\ \text { Aq. ad. } & 3 \mathrm{i}\end{array}$

t.d.s.

together with occasional doses of a carminative for his attacks of flatulence. $\mathrm{He}$ also for a long time took liq. trinitrin $m i$, and liq. strychninae $m$ iii t.d.s. Huchard strongly recommends vaso-dilators for this condition. 


\section{CHAPTER VIII.}

\section{PERICARDITIS.}

Pericarditis.-The pericardium, or membranous sac which contains the heart, like other serous membranes, is subject to inflammation, which in this case is most frequently of rheumatic origin, and is most often seen in the case of children. As to the diagnosis, there is not much difficulty in a case which is followed carefully day by day, but when seen for the first time, the difference between dilatation of the heart and pericardial effusion is by no means easy to make out. Often, too, pericarditis gives rise to no symptoms, occurring along with endocarditis, so that unless a careful examination of the heart be made, it will readily pass unrecognised. So close is the connection between rheumatism and pericarditis, that the pericardial inflammation is not to be looked upon as a mere complication of rheumatism, but as an integral part of the disease. According to Dr. Poynton, it is just as essentially a primary lesion as the joint 
affection, and in the young it is often the only lesion in the attack. The pericardium is not a vital structure, and therefore its inflammation is only dangerous ( $I$ ) as affording a large surface for the absorption of toxic products ; (2) from the inflammation extending to the heart muscle ; (3) the effusion, by its volume, compressing the heart and impeding its diastole. ${ }^{1}$ The prognosis depends mainly on the extent to which the cardiac muscle is involved, and this is fairly indicated by the degree of dilatation and disturbance of the action of the heart. Age influences the prognosis, because the younger the child, the greater is the liability to pericardial infection in rheumatism, also to the invasion of the heart muscle. The influence of associated diseases is also important, thus chronic nephritis and tuberculosis add much to the gravity of the prognosis. The general immediate prognosis of the rheumatic form of pericarditis is certainly favourable, more particularly in children, in whom the attack is rather sub-acute and insidious than in adults. As in other conditions which we have dealt with, the prognosis depends very much on the degree to which the cardiac muscle is attacked by the inflammatory process. Sometimes death may occur in 2-3 days, and then there is usually found little or no effusion, but great cardiac dilatation, and ${ }^{1}$ Osler and M'Crae's System of Medicine, vol. iv. p. $6 \mathrm{I}$. 
apparently the severity of the inflammation had paralysed the cardiac muscle. The amount of effusion into the pericardium, and the rapidity with which it is poured out are important factors in the prognosis.

Consequently pericarditis must always be regarded as a most serious affection of the heart, owing to the fact that it is so often intimately bound up with myocarditis, which may lead to death in a few days ; but this is not a common occurrence. Speaking generally, the immediate prognosis is favourable, but, owing to the formation of adhesions, the heart is often seriously crippled, so that the prospect of a long life is distinctly diminished. When the inflammation of the cardiac muscle itself has been slight, the heart may rapidly contract down again to its normal size, and be little the worse; but if the inflammation is protracted and severe, involving great injury to the myocardium, the heart is unable to recover for some time, and in the process of repair fibrous tissue takes the place of the damaged muscle, so that the heart is permanently weakened, and the pericardium may become adherent to it. In the case of adults, the ultimate outlook is usually better; no doubt the symptoms may be more acute at the time of the attack, but its duration is generally short, and the heart escapes without serious damage. 
In mild cases of dry pericarditis, even though the general symptoms are marked, the friction rub may disappear in a few days and convalescence be rapid; in this form there is no danger to life. The more remote danger, in the case of children, is pericardial adhesion, which takes place gradually, so that the heart never regains its normal size and vigour. For, after recovery, the child remains weakly, pale, and short of breath, the heart being permanently crippled on account of the pericardial adhesions, together with the persisting changes in the myocardium, caused by the inflammation and the valvular affections, which so often co-exist. An adherent pericardium is, therefore, a very serious matter in childhood, but in adult life the outlook is favourable. Not infrequently pericardial adhesions are found post mortem in old people, which do not seem to have hampered their activity much during life. Pericardial adhesions sometimes, though rarely, occur independently of any other disease, and in such cases, when not extensive, the prognosis may be quite favourable. More usually they are associated with some lesion of one of the valves, or they bind down the heart to the surrounding parts, and in such cases the outlook is always serious.

Treatment.-At the outset we may fittingly quote Balfour, " Pericarditis, like other acute inflammations occurring in an otherwise healthy individual may 
be expected to run a favourable course, if not unduly treated."

It must first be realised in the treatment of pericarditis, that the danger seldom arises from the mere fact of the inflammation of the serous membrane, but is due (I) to the pressure of accumulated fluid hampering the action of the heart, (2) to the occurrence of inflammation in the wall of the heart itself, either from simultaneous affection, or owing to an extension from the pericardium. Hence there are two main principles to be observed-

I. To combat the inflammation of the pericardium.

2. To prevent the failure of the heart.

Local measures are of the first importance in reducing the inflammation, and of these I have found an ice bag to the praecordium the most efficacious; it relieves pain, and steadies the action of the heart, probably by stimulating reflexly the vaso-motor nerves of the pericardium, causing contraction of the vessels and diminution of the blood supply. Leeching, hot applications, and small blisters do not seem so satisfactory, but at times the best results are obtained by the alternation of hot and cold applications. If these local measures do not relieve the pain, restlessness and dyspnoea, then opium or morphia should be given. Though it is common to administer salicylates internally, they 
do not seem to have much effect when the cardiac structures are affected.

It is important to give plenty of nourishment, and to secure sound sleep, even by hypnotics if necessary. When cardiac stimulants are wanted during the acute stage, ammonia, alcohol, caffeine, strychnine, and strophanthus are most useful, but digitalis is best avoided, lest by its action on the arterioles the blood-pressure may be unduly raised, and so a strain be put on the injured heart. When the dyspnoea is great, as a result of pulmonary congestion, venesection may be used, for in any condition attended by overstrain and distension of the right ventricle venesection is not dangerous.

Pericardial effusion, when moderate in degree, does not require any treatment, as it will probably be absorbed, beyond rest in bed, which relieves the heart of work as far as possible; care, however, must be taken not to allow the patient to sit up suddenly, as a fatal syncope might occur should the effusion be large. Absorption is sometimes aided by diuretics, saline purgatives, and small blisters to the praecordium. The diet should contain little fluid, and salt should be excluded, as far as possible, from it; apart from this, the diet should be generous, as the tendency is to degeneration of the wall of the heart from infection and insufficient nourishment. 
When these measures have little effect, and when with large effusion there are signs of cardiac disturbance, paracentesis should be performed without delay, as death from syncope may occur; but we must remember that the cardiac embarrassment is due chiefly to disease of the myocardium and the consequent dilatation, and only slightly, probably in most cases not at all, to the presence of the effusion. It is interesting to know that paracentesis pericardii was first performed in 1649 by Riolan, the well known opponent of Harvey, and then not again till I794, when it was performed by Senac. We do not at present possess any means of breaking down pericardial adhesions ; it is necessary therefore to recognise that the heart is to some extent handicapped, and the only aim of treatment must be to maintain the compensatory hypertrophy. This means that all strains must be avoided, and the heart only allowed to work within the limits of its capacity. The general lines of treatment do not therefore differ from those employed in other forms of cardiac disease. 


\section{CHAPTER IX.}

THE TREATMENT OF SPECIAL SYMPTOMS.

Insomnia.-This is often one of the most troublesome symptoms in chronic heart disease. So often is it associated with dyspnoea, that if we can treat the latter successfully, the sleeplessness will disappear. Apart from the discomfort to the patient caused by the continual want of sleep, the heart itself suffers directly, because it does not obtain that amount of rest which is ensured to it by the slower beating during sleep. General methods of inducing sleep, such as warmth to the skin, and specially to the feet, need hardly be insisted on here. The hypnotic which I have found most satisfactory in these cases is chloralamide given in gr. $\mathrm{xxv}-\mathrm{xxx}$ doses. This drug has the advantages of chloral as an hypnotic without being depressant to the heart. It is, in fact, chloral combined with an amide group (formamid). This body is slowly split in the organism, releasing the chloral sufficiently fast to produce the hypnotic effect, but not the cardiac 
and respiratory depression; the amido body, being converted to ammonia, has a stimulating effect, which counteracts the depression of chloral. It is well to combine it with some bromide, which will prevent any headache, which otherwise may supervene the following day. It is best given in solution, as, when taken in the form of a powder, it is very slowly absorbed, so that the hypnotic effect may not appear till the next day. It may be given in a little brandy and water, as it is rather insoluble in water, or may be suspended. It has a somewhat unpleasant taste, which may be disguised by ext. glycyrrhizae liq.

Paraldehyde is another somewhat similar drug, which is quite safe, and acts quickly, best given in a cachet in $3 \mathrm{i}$ dose. There is, however, the great disadvantage of its having an extremely nasty taste and imparting an unpleasant smell to the breath, which may last many hours; it does not therefore possess any advantage over chloralamide.

Trional is a safe and satisfactory hypnotic in cardiac cases; it may be given in doses of $\mathrm{gr}$. $\mathrm{xv}-\mathrm{xx}$. There is little taste, and it is best administered in powder form, but it can be given in capsules or dissolved in a little brandy or whisky, or stirred up with milk and water. It should be given about a couple of hours before bedtime, and if it seems likely to prove ineffectual, the dose may be repeated 
in 3-4 hours. It acts more rapidly than sulphonal, and is eliminated more promptly, so that it has less effect the following day; it is also said to be less toxic.

Sulphonal is a drug very similar to trional, but it is slower in its action, and so should be administered 3-4 hours before bedtime; the effect often lasts on into the following day. It may be given in dose of gr. $x \mathbf{x}$ in cachet or suspended in mucilage.

Veronal has come into vogue of recent years, and in my experience has proved to be quite a reliable hypnotic in these cases; but it is apt to lose its effect when administered continuously. It may be given in doses of gr. $\mathrm{v}$-viii in cachet, half an hour before bedtime.

Urethane (ethyl carbamate) is said to be useful in doses from I5-20 grains, but I have had no experience of it in this connection. It has the advantage of being freely soluble in water.

Sometimes the cause of the insomnia may be an atheromatous condition of the cerebral vessels, which by diminishing their power of contraction permits the blood to flow freely through the brain, so that the patient cannot get to sleep. In such cases large doses of iodide and bromide, combined with rest and massage, are most useful.

When there is nothing in the condition of the lungs to contraindicate opium, then nepenthe (which 


\section{TREATMENT OF SPECIAL SYMPTOMS IO7}

is the same strength as tinct. opii) combined with bromide, is an excellent hypnotic to administer, particularly in the case of children.

Morphia subcutaneously may be necessary in obstinate cases, and particularly in aortic disease, when there is pain; there is no objection to giving it, and indeed it often seems to act as a cardiac tonic.

Cough is a most frequent symptom in heart disease, and is often suggestive of an early stage of cardiac failure; in children, cough is sometimes quite a diagnostic feature of heart disease. It may be relieved by giving drinks of hot milk with seltzer water, which assists expectoration, or by a stimulating expectorant, such as ammonium carbonate combined with senega and spirits of aether. When the cough is of a more hacking character, the pil. ipecac. cum scilla (B.P.) gr. $v$ twice a day will be useful, or a teaspoonful of syrupus codeiae combined with an equal amount of syrupus pruni virgineanae.

Very painful in particular is the cough of aortic disease, which is sometimes due to pressure of the dilated aorta on the trachea, or upon the laryngeal nerves, and it may be necessary to give morphia.

Dyspnoea.-Apart from the shortness of breath, which is one of the cardinal symptoms of heart disease, there often occur, especially at night, severe paroxysms of dyspnoea, which have received the 
somewhat objectionable name of cardiac asthma, for the dyspnoea is not chiefly expiratory, as in true asthma, and fine vesicular râles are heard throughout the attack, and not merely at the end of the attack, as in asthma proper. It need hardly be said that in such cases regulation of the bowels is most important, and all heavy meals in the evening must be steadfastly avoided. Mustard poultices and dry cupping over the back of the chest are often useful. In young and robust subjects, with signs of venous engorgement and cyanosis, the abstraction of $\mathrm{I5}^{-20}$ ounces of blood will give great relief, and enable the cardiac tonics to act more efficiently. Inhalations of oxygen often give great relief; the patient should not make any effort to take deep breaths, but the oxygen should be allowed to stream over his mouth and nose under moderate pressure, the patient avoiding any kind of muscular effort. It is also said by some that oxygen inhalations diminish the viscosity of the cyanotic blood in many cases, and therefore diminish the peripheral resistance.

A small dose of morphia (gr. $\frac{1}{8}-\frac{1}{10}$ ) given at night hypodermically, and combined with atrophine gr. $\frac{1}{150}$, by reducing the irritability of the respiratory centre and deepening the respiration, will relieve the dyspnoea, and thus readily remove this very distressing symptom. 


\section{TREATMENT OF SPECIAL SYMPTOMS IO9}

Haemoptysis does not require any active treatment ; as a rule, it is not a serious symptom in heart disease, but complete rest should for the time be insisted upon.

Flatulence may be relieved by thymol gr. I or creosote $m_{\frac{1}{2}}$ two or three times a day after food. The compound assafoetida pill of the British Pharmacopoeia is often most useful. I generally prefer a simple carminative mixture, such as

R

$\begin{array}{ll}\text { Essent. menth. pip. } & m_{\mathrm{v}} \\ \text { Tinct. capsici } & m_{\mathrm{ii}} \\ \text { Syrupi zingiberis } & \mathrm{m}_{\mathrm{xv}} \\ \text { Aq. chlorof. ad } & \text { 亏f. }\end{array}$

Vomiting is a serious symptom in heart disease, and is often the herald of a fatal termination, owing to the serious strain which is put upon the heart by the effort of vomiting. When persistent, it will necessitate the abstention from all solid food for a time, only iced milk or peptonised milk being given and brandy if necessary. If digitalis is being given at the time it must, of course, be withdrawn. Large doses of bismuth are often effective in relieving the condition, and oxalate of cerium gr. $\mathrm{v}$ will sometimes prove successful when other better known drugs fail.

Dropsy.-It is most important to relieve this condition, and it is usually done by means of excessive 
diuresis, also by diaphoretics and hydragogue purges. It is worth remembering that a milk diet, owing to the lactose it contains, has a useful diuretic effect. Fortunately the cardiac tonics are also diuretics and, while strengthening the heart, they also raise the blood-pressure in the renal glomeruli, and so increase the flow of urine. The infusion of digitalis is said to have a stronger diuretic effect than the tincture; one should begin with $\xi f$ every 4 hours for a few days, and its action be carefully watched, and then it should be gradually diminished. Strophanthus and caffeine have also diuretic effects. Calomel in doses of 2 grains three times a day is an effective diuretic, but it is not suitable on all occasions. Acetate or nitrate of potash, and particularly spirits of juniper and decoction of broom tops are all helpful. The more modern drugsdiuretin and theobromine I have found most useful, particularly the last-named in doses of to grains three times a day; its action is confined to stimulating the secreting epithelium of the kidneys : it has no influence on the heart; diuretin is best given in xv-grain doses every four hours.

If there is much accumulation of fluid in the abdomen, we shall not in many cases obtain much diuresis, until we have resorted to tapping, which is conveniently done by means of Southey's tubes. Similarly, punctures may be made in the skin of 


\section{TREATMENT OF SPECIAL SYMPTOMS III}

the legs to enable the serum to drain away. Great cleanliness is required for this little operation, as the skin in this condition is very ready to become inflamed.

The removal of the fluid can be greatly assisted by cathartics. We may give pil. hydrargy. gr. $\mathrm{v}-\mathrm{x}$ at night, followed by a teaspoonful of compound jalap powder the next morning. Or a saturated solution of Epsom salts (张) every 2 hours, till a result is produced, will be found most effective; the addition of some syrup of ginger will prevent the feeling of nausea. 




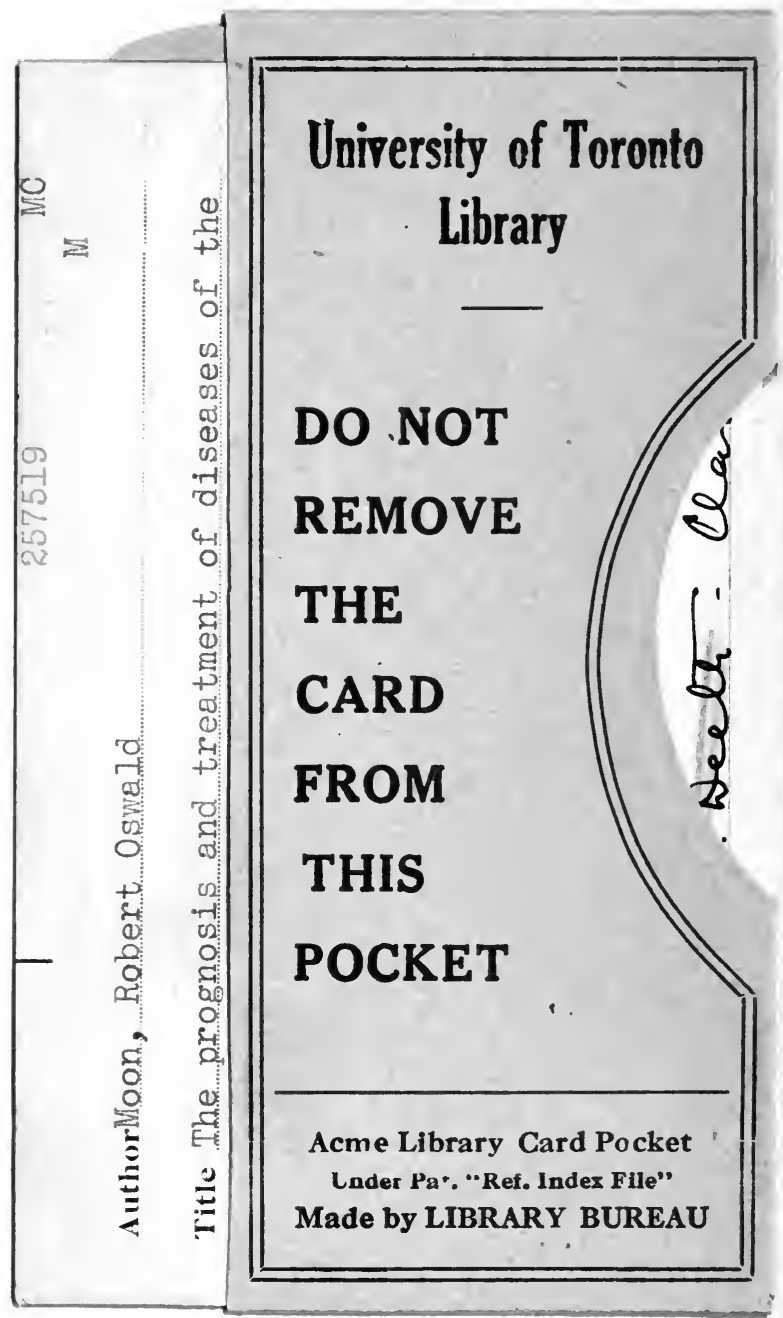


